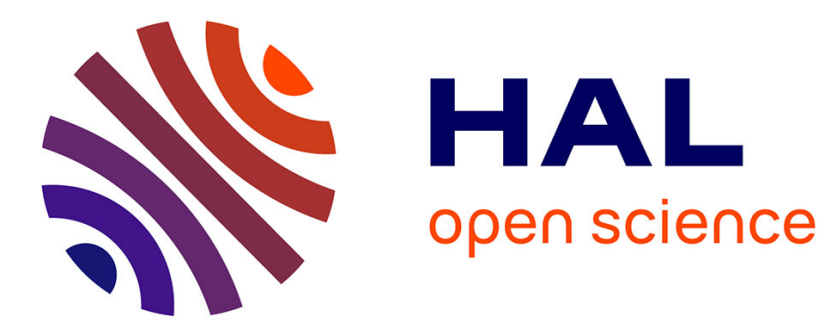

\title{
Two Independent Triggers for the Indian Ocean Dipole/Zonal Mode in a Coupled GCM
}

Albert S. Fischer, Pascal Terray, Éric Guilyardi, Silvio Gualdi, Pascale Delécluse

\section{- To cite this version:}

Albert S. Fischer, Pascal Terray, Éric Guilyardi, Silvio Gualdi, Pascale Delécluse. Two Independent Triggers for the Indian Ocean Dipole/Zonal Mode in a Coupled GCM. Journal of Climate, 2005, 18, pp.3428-3449. 10.1175/JCLI3478.1 . hal-00124087

\section{HAL Id: hal-00124087 \\ https://hal.science/hal-00124087}

Submitted on 29 May 2016

HAL is a multi-disciplinary open access archive for the deposit and dissemination of scientific research documents, whether they are published or not. The documents may come from teaching and research institutions in France or abroad, or from public or private research centers.
L'archive ouverte pluridisciplinaire HAL, est destinée au dépôt et à la diffusion de documents scientifiques de niveau recherche, publiés ou non, émanant des établissements d'enseignement et de recherche français ou étrangers, des laboratoires publics ou privés. 


\section{Two independent triggers for the Indian Ocean Dipole / Zonal Mode in a coupled GCM}

\section{ALBERT S. FISCHER AND PASCAL TERRAY}

Laboratoire d'Océanographie Dynamique et de Climatologie, Institut Pierre Simon Laplace, Paris, France

\section{ERIC GUILYARDI}

Center for Global Atmospheric Modeling, University of Reading, United Kingdom and the Laboratoire des Sciences du Climat et l'Environnement, Gif-sur-Yvette, France

\section{SILVIO GUALDI}

Istituto Nazionale di Geofisica e Vulcanologia, Bologna, Italy

PASCALE DeleCLuse

Laboratoire des Sciences du Climat et l'Environnement, Gif-sur-Yvette, France

submitted to Journal of Climate

revised 28 September 2004

Corresponding author address: Albert Fischer, now at IOC/UNESCO, 1 rue Miollis, 75732 Paris cedex 15, France.

E-mail: a.fischer@unesco.org 


\section{ABSTRACT}

We address the question of whether and how tropical Indian Ocean Dipole or Zonal Mode (IOZM) interannual variability is independent of El Niño-Southern Oscillation (ENSO) variability in the Pacific, in a comparison of twin 200-year runs of a coupled climate model. The first is a reference simulation, the second has ENSO-scale variability suppressed with a constraint on the tropical Pacific wind stress. The IOZM can exist in the model without ENSO, and the composite evolution of the main anomalies in the Indian Ocean in the two simulations is virtually identical. Its growth depends on a positive feedback between anomalous equatorial easterly winds, upwelling equatorial and coastal Kelvin waves reducing the thermocline depth and sea surface temperature off the coast of Sumatra, and the atmospheric dynamical response to the subsequently reduced convection.

Two IOZM triggers in the boreal spring are found. The first is an anomalous Hadley circulation over the eastern tropical Indian Ocean and Maritime Continent, with an early northward penetration of the southern hemisphere southeasterly trades. This situation grows out of cooler sea surface temperatures in the southeastern tropical Indian Ocean left behind by a reinforcement of the late austral summer winds. The second trigger is a consequence of a zonal shift in the center of convection associated with a developing El Niño, a Walker cell anomaly. The first trigger is the only one present in the constrained simulation, and is similar to the evolution of anomalies in 1994, when the IOZM occurred in the absence of a Pacific El Niño state. The presence of these two triggers - the first independent of ENSO, the second phase-locking the IOZM to El Niño-allows an understanding of both the existence of IOZM events when Pacific conditions are neutral, and the significant correlation between the IOZM and El Niño.

\section{Introduction}

The concept of an interannual Indian Ocean Dipole mode of variability with cold surface temperature anomalies in the southeastern tropical Indian Ocean (SETIO) and warmer anomalies in the western tropical Indian Ocean (WTIO), coupled to easterly wind anomalies, was described by Saji et al. (1999) and Webster et al. (1999), though these types of anomalies were also noted in an earlier study (Reverdin et al. 1986). These anomalies are linked to precipita- 
tion variability in East Africa and over Indonesia (Clark et al., 2003; Black et al. 2003) and other regions (Ashok et al., 2001; Lareef et al., 2003; Saji and Yamagata, 2003a), and so understanding their dynamics with a view towards prediction has an important social dimension. Saji et al. (1999) claimed that the dipole was a mode of variability confined to the Indian Ocean independent of ENSO. Webster et al. (1999) suggested a coupled mechanism allowing the growth of anomalies and cycling of the dipole mode based on the Indian Ocean alone.

The contention that the dipole mode is independent of ENSO has received some recent attention. Saji et al.'s (1999) interpretation of the dipole mode as independent was based on dipole years without El Niño events, and included a modal definition derived in part from the second EOF of tropical sea surface temperature (SST) anomalies. This was disputed by Dommenget and Latif (2002), who pointed out that the orthogonality of this mode did not necessarily mean that the physical mode with a similar pattern was independent. Allan et al. (2001) demonstrated that significant correlations exist between anomalies in the tropical Indian Ocean and ENSO when seasonal values are used. Yamagata et al. (2002) and Behera et al. (2003) responded with further evidence and arguments of the statistical independence of the dipole mode from ENSO.

A number of studies (Chambers et al. 1999; Yu and Rienecker 2000; Annamalai et al. 2003) have examined the dynamical mechanisms connecting Pacific El Niño variability and dipole-like anomalies in the Indian ocean. Gualdi et al. (2003) described these mechanisms in a coupled model, while Baquero-Bernal et al. (2002) used a series of forced atmospheric and coupled model simulations to show statistically that dipole-like variability in the Indian Ocean was largely associated with ENSO. Li et al. (2003) outlined the Indian Ocean coupled feedbacks that drive the dynamics of the dipole - the two positive feedbacks being the wind-thermocline-SST feedback (Bjerknes 1969), and a seasonal wind-evaporation-SST (WES) feedback off the coast of Sumatra - while maintaining that ENSO variability was one major external forcing for the dipole.

The two poles of the dipole described by Saji et al. (1999) are in fact weakly anti-correlated in phase (Baquero-Bernal et al. 2002), and the SETIO pole has stronger variability. We 
therefore adopt a different nomenclature, the Indian Ocean Zonal Mode (IOZM, Clark et al., 2003), to describe the near-equatorial interannual variability centered off the coast of Sumatra.

In order to separate the variability in the Indian Ocean driven by ENSO variability in the Pacific from that which is intrinsic to the Indian Ocean coupled system, we conceived an experimental framework of numerical experiments with a coupled general circulation model (CGCM). A long simulation is constrained to suppress ENSO, and compared with a reference simulation. Several datasets are used to help judge the validity and biases of the model and the robustness of the results. The analysis of the remaining Indian Ocean variability in the absence of ENSO forcing reveals two different triggers of the IOZM, including one that is an avenue for phase-locking between Pacific El Niño modes and the cold phase of the IOZM.

The coupled model, its systemic biases, and our method of suppressing ENSO are described in the following section. The evolution of the IOZM with and without ENSO are described in Section 3, with the precursory conditions triggering its development examined in more detail in Section 4. The results, including comparisons with climatological data, are discussed in Section 5 before the summary in Section 6.

\section{Methods: The coupled model, validation, and constraining the model ENSO}

\section{a. The coupled model}

The model (described in detail in Gualdi et al. 2003a and Guilyardi et al. 2003) consists of two independent dynamical components linked by a coupler, and was developed during the EU Scale Interaction Experiment (SINTEX). The atmospheric component is ECHAM-4 (Roeckner et al. 1996), a version of the European Centre for Medium-range Weather Forecasting (ECMWF) atmospheric model adapted to climate simulations. Here it is run at T30 spectral resolution, corresponding to a horizontal resolution of about $3.75^{\circ}$, with 19 vertical layers.

The ocean component is the OPA8 ocean model (Madec et al. 1998) in its ORCA2 global configuration. The horizontal resolution is variable, with a nominal resolution of $2^{\circ}$ in longitude, and $1.5^{\circ}$ in latitude with an increase to $0.5^{\circ}$ near the equator. There are 31 vertical levels, 
with $10 \mathrm{~m}$ resolution in the top $100 \mathrm{~m}$. The system does not include an interactive cryosphere, and ice cover is relaxed towards climatology.

The two components are coupled with the OASIS 2.4 (Valcke et al. 2000) coupler every three hours, resolving the diurnal cycle, with no flux corrections. The initial condition for the ocean is the Levitus (1982) climatology, for the atmosphere a spinup of a forced atmospheric simulation. For the first two years the ocean is run in robust-diagnostic mode, with a restoring to the climatological state in the interior, away from boundaries.

\section{b. Climatological datasets}

We use a series of climatological products and analyses for both comparison and validation of the model-produced climate mean state and variability, and to study the mechanisms of IOZM events with and without ENSO in more detail. The simple ocean data assimilation (SODA, Carton et al. 2000) ocean climatology, covering the years 1950-2000, is used for SST and thermocline depth. There is a lack of long-term subsurface observations in the IndoPacific region, particularly in the Indian Ocean. The product away from the surface is then largely an ocean model response to surface forcing in these data-poor regions. The Reynolds and Smith (1994) SST climatology was also considered, and yields similar results to SODA SSTs. For comparisons at the air-sea interface, we use the Southampton Oceanography Center (SOC, Josey et al. 1999) climatology of wind stress and heat flux components, based on the years 1980-1997. For sea level pressure (SLP), surface and upper-level winds, we use the NCEP reanalysis (Kalnay et al. 1996), covering the years 1950-2000. For precipitation, we use the CPC Merged Analysis of Precipitation (Xie and Arkin 1997), covering the years 19792002. In comparing the power spectra of long timeseries from the model runs, we use an equatorial Pacific wind index, covering $8^{\circ} \mathrm{S}-8^{\circ} \mathrm{N}, 150^{\circ} \mathrm{E}-140^{\circ} \mathrm{W}$, from 1854-1995 (Mitchell 2003), while other atmospheric and oceanic indices are derived from the NCEP and Reynolds SST reanalyses. 


\section{c. The coupled model representation of the tropical Indo-Pacific}

\section{1) MEAN STATE, INCLUDING SEASONAL CYCLE AND BIASES}

The 200-year reference simulation (REF) is described in Guilyardi et al. 2003. The mean state of the tropics remains quite stable during the integration. The mean surface temperatures in the Indo-Pacific region compare well with observations (top two panels Fig. 1). The major model biases are a strong upwelling at the equator in the central and eastern Pacific associated with strong trade winds (a too-strong cold tongue), a weak and divided western Pacific warm pool, and an eastward extension of warm waters in the southern tropical Pacific, associated with the unrealistic formation of a double ITCZ. These biases are common in other modern coupled models (AchutaRao et al. 2002). The mean state in the tropical Indian Ocean compares very well with observations, though in the seasonal cycle there is a bias towards cool temperatures in the eastern tropical Indian Ocean (ETIO) during the boreal fall. The ocean subsurface structure (not shown) reflects the mean biases in the Pacific, and in the Indian Ocean reveals a bias towards a shallow thermocline in the ETIO. Outside of the equatorial zone, the mean thermocline depth structures in both the Pacific and Indian Oceans exhibit some strong biases, in the Pacific influenced by the double ITCZ and the associated unrealistic wind structures, and in the Indian Ocean associated with the strong zonal winds and lack of strength in the Asian Monsoon circulation (Roeckner et al. 1996).

The coupled model has a systematic bias which favors variability in the SETIO region. This is a bias in the seasonal cycle of Indian Ocean equatorial winds (see Terray et al. 2004a for a description of how this affects ENSO-monsoon interactions in the same model). The model climatological thermocline is therefore shallower than observed in the boreal fall, at the season of the maximum of the IOZM. Several key indices for the IOZM are shown in Fig. 2. The mean observed seasonal cycle of equatorial zonal winds in the Indian Ocean has two westerly peaks during the transition seasons between the monsoons. Westerly winds provoke an equatorial downwelling Kelvin wave response, which rapidly translates eastwards in both a current, the Yoshida-Wyrtki Jet (Wyrtki 1973) and thermocline depth response (seen in the $20^{\circ} \mathrm{C}$ isotherm depth), affecting the thermocline along the coast of Sumatra through coastal Kelvin waves (Clarke and Liu 1994; Meyers 1996). A projection of this downwelling onto 
westward-propagating long Rossby waves then carries this information offshore, increasing thermocline depth in a region offshore larger than the Rossby radius. The arrival of the Yoshida-Wyrtki Jet in spring and fall thus deepens the thermocline in the SETIO. In the model, however, the spring equatorial westerly winds, equatorial jet, and thermocline response exist (with a peak delayed by one month), but the mean fall winds are mildly easterly rather than westerly. The result is that the mean depth of the simulated thermocline off the coast of Sumatra decreases from September through November, to a depth of about $80 \mathrm{~m}$, against the SODA estimate of about $120 \mathrm{~m}$.

The erroneous winds in the equatorial Indian Ocean during boreal fall can be traced to the model's placement of a strong zone of convection in the southwestern tropical Indian Ocean northeast of Madagascar. This in turn can be traced both to somewhat warmer than observed SSTs in the coupled simulation, and to difficulties with the atmospheric convective scheme, which even in forced atmospheric simulations (at both T30 and T42 resolutions) with climatological SSTs creates a boreal fall Indian Ocean zonal gradient in precipitation biased towards the west, driving the Indian Ocean Walker circulation in the wrong direction. This bias is absent in a T106 version of the same coupled model (S. Masson, personal communication).

The bias in the boreal fall SETIO thermocline depth is added to by a smaller bias in the seasonal cycle of upwelling-favorable winds along the Sumatra coast, influenced by the quicker-than-observed northward movement of the Mascarene anticyclone in boreal fall (Terray et al. 2004a). The observed seasonal cycle along the Sumatra coast follows the shifts in the centers of atmospheric convection (see Fig. 2), with northwesterly downwelling-favorable winds during the austral summer Australian monsoon (DJF), and southeasterly upwellingfavorable winds building through the boreal summer monsoon season (JJAS), peaking at its end. The model produces a reasonable seasonal cycle, with a bias towards strong upwelling winds during the SW monsoon season.

These two wind biases both favor upwelling and a shoaling of the SETIO thermocline in the boreal fall, sensitizing the system by allowing a smaller initial disturbance to develop into the Bjerknes-type positive feedback between ocean and atmosphere that occurs in the growth 
phase of the IOZM (see Section 3). They explain why the model has a higher SETIO variability than observed (detailed below), a fact worth keeping in mind in the analysis to follow.

\section{2) INTERANNUAL VARIABILITY}

The amplitude of interannual variability in the SST reveals an ENSO that is smaller than observed (Fig. 3 top two panels). The model also produces an ENSO with a higher frequency than observed, with a peak between 2 and 3 years (first three panels of Fig. 5, see also Guilyardi et al. 2004 for further details).

The model supports an IOZM - its evolution is described by Gualdi et al. (2003b) for the T42 version of the coupled model (and is similar to that seen here), reproducing the main features described by Saji et al. (1999). The Indian Ocean SST variability is overemphasized off the coast of Sumatra, and in the subsurface over a large part of the ETIO (Fig. 4 top two panels), as expected from the model biases described above.

The seasonal maximum in interannual variability in the Indian Ocean is anchored in the seasonal cycle, for the SETIO $\left(70-90^{\circ} \mathrm{E}, 10^{\circ} \mathrm{S}-0^{\circ}\right)$ it is in the boreal fall, for the WTIO (50$70^{\circ} \mathrm{E}, 10^{\circ} \mathrm{S}-10^{\circ} \mathrm{N}$ ) it arrives a few months later. The tropical variability in the Indian and Pacific Oceans is significantly correlated when seasonally stratified (Allan et al. 2001), these relationships are shown in Fig. 6 for observations and the REF simulation. The SETIO index of SST anomaly is anticorrelated with the Niño3.4 SST anomaly (with just over 99\% significance), and the WTIO is more strongly correlated with Niño3.4, with the Pacific signal leading by about one season. This correlation is reproduced quite well in REF (although the model has a tendency towards a significant biennial signal not seen in the observations) giving some confidence in the coupled model's ability to reproduce the relationship between Indian and Pacific tropical variability.

\section{d. Removing ENSO from the model}

The ENSO cycle depends on a coupled interaction of atmosphere and ocean in the tropical Pacific Ocean, and thus can be suppressed in a coupled model by constraining one of the agents of exchange between components (Fig. 7). These are the SST, which as entry into the atmospheric model in part determines the air-sea heat flux, forcing the atmospheric dynamics, 
producing a surface wind stress. The wind stress and heat flux are the forcing for the oceanic component, which through its own dynamics then produces a distribution of SST. The SST and heat flux are the agents through which thermodynamic atmosphere-ocean coupling occurs. A direct negative feedback exists between the two, with higher (lower) SSTs generally yielding a smaller (larger) heat flux from atmosphere to ocean through an increase (decrease) in the latent, sensible and longwave heat fluxes. The wind stress on the ocean is the agent of dynamic coupling, and sensitized by a thermocline in close proximity to the surface can provide the positive Bjerknes-type feedback necessary for coupled anomaly growth and for ENSO.

Previous studies have used a number of regional constraint methods to artificially control the physics of the tropical Pacific Ocean in coupled models. Elliott et al. (2001) used a very strong SST restoring term, in essence constraining the oceanic surface heat flux to reproduce a given pattern of SST. Strong fluxes may be necessary to maintain a given SST trajectory against evolving ocean and atmospheric dynamics. Given the quick link between the Indian and Pacific oceans via the Indonesian throughflow (ITF), it is not clear that this constraint on the tropical Pacific Ocean would not adversely affect the dynamics of the Indian Ocean by changing the mean properties or variability of the water masses in the ITF. Baquero-Bernal et al. (2002) used a different constraint, passing to the atmosphere a climatological SST.

Here we find that a third method, constraining the wind stress seen by the ocean, worked best at suppressing the interannual variability associated with ENSO while keeping the tropical Pacific mean state in both ocean and atmosphere closest to the reference simulation. The constraint was applied in a limited domain covering the tropical Pacific (see Fig. 8). The latitudinal transition lines fall at the poleward edge of the subtropical gyres, and in the wind stress patterns roughly at the transition between the midlatitude westerlies and the trades, though this line varies with the seasons. The constrained model experiment (noENSO) was run for 200 years to match REF, constrained with the mean monthly climatology of REF rather than an observed climatology, in order to keep the comparison between simulations clean.

We here examine the mean state and variability of the ocean and atmosphere in order to both ensure that ENSO-scale variability has been suppressed, and to confirm that the constraint on the physics of the model has not distorted the mean state. 
The mean state of noENSO has changed little from REF in both the surface and subsurface oceanic fields. There is a small bias in the Pacific towards an eastern Pacific cold state (Fig. 1 bottom row) of less than $0.3{ }^{\circ} \mathrm{C}$ in the Pacific cold tongue region. A small bias in the depth of the $20^{\circ} \mathrm{C}$ isotherm (Z20) is found in noENSO compared REF in the eastern tropical Pacific (shallower by about $5 \mathrm{~m}$, not shown), mirroring the surface bias. The mean state of the Indian Ocean is indistinguishable between noENSO and REF at the surface, and nearly identical in the subsurface. The mean wind stress field produced by the atmosphere in noENSO is very close to the REF field, with differences peaking at $0.005 \mathrm{~N} \mathrm{~m}^{-2}$, while means in the trade wind regime of the tropical Pacific are typically $0.03-0.1 \mathrm{~N} \mathrm{~m}^{-2}$. Despite the artificial break in the physics in the dynamical connection between atmosphere and ocean, the atmosphere produces a wind stress field that is closely matched to imposed wind stress, and the coupling is therefore fairly well closed, with little dynamical distortion introduced by the artificial constraint.

The interannual variability of the equatorial Pacific surface ocean and subsurface in noENSO has been greatly reduced when compared to REF. The variability of ENSO with respect to the mean seasonal cycle can be seen in SST as the tongue of high variability extending across the equatorial Pacific Ocean, concentrated in the east (Fig. 3 top right). In noENSO, in response to the fixed wind stress forcing in the constrained zone, the SST variability in the equatorial waveguide is dramatically reduced (Fig. 3 bottom row), most strongly directly on the equator, where wind-driven upwelling dynamics are the dominant thermodynamic control. The wind stress constraint is a very strong constraint on the ocean dynamics, as the reduction in variability in Z20 between noENSO and REF demonstrates (Fig. 4 bottom row), with a considerable reduction in a large region in the tropics, particularly strong on the equator and along the eastern edge of the Pacific Ocean where wind-generated equatorial and reflected coastal Kelvin waves are a large part of the dynamics. The amplitude of the variability of the Indian Ocean in noENSO, in both SST and Z20, is little reduced from REF (lower right of Figs. 3 and 4). This last point is revisited in the next section.

The noENSO constraint is quite successful at removing atmospheric signals at ENSO timescales, and removing the ENSO peak in Pacific Ocean indices (Fig. 5). On the atmospheric side, two typical indices for ENSO variability are the zonal wind stress over the tropi- 
cal Pacific, and the sea-level pressure at Darwin, one pole of the Southern Oscillation. The noENSO simulation has fairly white spectra for these atmospheric indices, demonstrating that atmospheric variability on the ENSO timescale in the Pacific sector has been effectively suppressed. On the oceanic side, the power spectra of the Niño3.4 SST anomaly index, and an anomaly index further east (EPAC, incorporating the major region of remaining Pacific variability in noENSO, $120-90^{\circ} \mathrm{W}, 10^{\circ} \mathrm{S}-10^{\circ} \mathrm{N}$ ), both show that the noENSO constraint acts strongly on the ocean. The energy of variability on the oceanic side in the Pacific has been dramatically reduced in noENSO.

In the Indian Ocean (bottom row of Fig. 5), the power spectra of SST anomalies in each of the 2 runs remain quite close to each other. In the western Indian Ocean, the only difference between REF and noENSO is a mild, barely significant reduction in variability in the model's ENSO time band. In the SETIO region the only difference between noENSO and REF is a very slight reduction of the 2-year signal, though a wavelet analysis reveals a few periods of remaining significant power (not shown).

An inspection of a histogram of the SETIO index variability reveals a significant departure from a Gaussian distribution, however, in a negative tail that is asymmetric with the positive anomaly side, in both the REF and noENSO simulations (Fig. 9), as well as to a lesser extent in SODA, an indication of a dynamical process that amplifies the cold phase of SETIO anomalies. This dynamical process is the IOZM.

The model-produced Indonesian Throughflow (ITF) has a seasonal cycle varying from 3 $\mathrm{Sv}$ in February to a peak of $14 \mathrm{~Sv}$ in September, which is essentially unchanged by the constraint in noENSO, further confirmation that the Pacific Ocean mean state has been successfully maintained despite the artificial constraint. The range of interannual variability in the ITF strength is reduced, as the variability is forced solely from the Indian side. The heat transport provided by the ITF from the Pacific to Indian Oceans also remains nearly constant in the mean between the two simulations, though again the interannual variability is somewhat reduced in noENSO.

A second method of constraint-constraining the SST seen by the atmosphere with the REF mean seasonal cycle in the tropical Pacific-was tested (the method employed by 
Baquero-Bernal et al. 2002), with a 100-year run. This proved an effective constraint for the atmosphere, producing spectra of the zonal equatorial Pacific wind stress and Darwin pressure slightly flatter and more white than the noENSO simulation. However, the ocean state in the constrained zone, with the negative thermodynamic feedback (Fig. 7) artificially cut, drifted with a red-noise spectrum, essentially a random-walk thermodynamic response to stochastic atmospheric forcing (Hasselman 1976; Frankignoul and Hasselman, 1977). The equatorial waveguide in the Pacific was also nearly as variable as in REF, with thermocline depth variability reflecting Kelvin waves driven by, but not coupled to, variability in the atmospheric wind forcing. The artificial constraint in this case strongly impacted the dynamics of the ocean component of the model, and the coupling in the constrained region was not well closed. The affected oceanic regions influenced the oceanic state neighboring the constrained zone, including the SETIO, and for this reason, analysis of this simulation was abandoned.

\section{IOZM evolution}

The comparison of REF and noENSO in the previous section reveals that the amplitude of the interannual variability in both the surface (SST) and subsurface (Z20) fields is little reduced in the tropical Indian Ocean in the absence of ENSO (see Fig. 3, Fig. 4, and Fig. 9). This section concentrates on the evolution and mechanism of the IOZM that is common to both simulations, with and without ENSO.

Composite IOZM events for REF and noENSO are constructed to compare the dynamical evolution of the two events. Years in which the seasonal SON SETIO anomaly is cold by greater than one standard deviation (37 events for REF and 29 for noENSO) are included in the composite. A statistical test based on a 95\% confidence level that a random drawing without replacement of an equivalent number of years from the 200 years of the REF or noENSO simulations would not have as large of an anomaly from the mean state as the composite (Terray et al. 2003) is used to mask fields in the figures. The evolution of key ocean and atmosphere anomalies are presented in Fig. 10 for REF, and Fig. 11 for noENSO. The use of alternate indices as indicators for the IOZM, such as the equatorial zonal wind in the Indian Ocean, yields similar years and therefore similar results (not shown). 


\section{a. Similarities in the IOZM evolution with and without ENSO}

The evolution of the IOZM anomalies during both the growth and decay phases in REF and noENSO is remarkably similar, and in most respects is the evolution described by Gualdi et al. (2003b). This is a coupled response of the ocean and atmosphere, with upwelling and cold SST anomalies in the SETIO, accompanied by anomalous easterly winds along the equator. The common points between the two runs are described here. A statistical test of the significance of the similarity in the REF and noENSO IOZM composites was performed by grouping the 37 REF and 29 noENSO simulation IOZM years, and repeatedly (9999 times) calculating the difference between the means of a random sample (without replacement) of 37 of these 66 years and the remaining 29 years. This yielded an estimate of the probability density function in which the actual difference between the REF and noENSO composites could be placed. From June through November the differences in SLP, precipitation, and lower and upper-level winds in the two composite sets are very small over the tropical Indian Ocean, showing a common evolution with (REF) and without (noENSO) the influence of ENSO (not shown).

The first anomalies in the composite evolution of the IOZM appear in the late spring, before the onset of the Asian Monsoon season. By June-July, an already coupled response over the SETIO region involves a lack of precipitation over the region close to the coast of Sumatra (Fig. 10, upper right panel), provoking a reduction in heating in the atmospheric column with a reduced latent heat release. The baroclinic atmospheric response to this off-equatorial heating anomaly includes a Rossby wave response to the west, with an increased SLP, and anticyclonic surface wind anomalies with an upwelling component along the Sumatra coast and an anomalous easterly component along the equatorial waveguide (Matsuno 1966; Gill, 1980; first row center panel of Figs. 10 and 11). In part collocated with the region of reduced precipitation is a region of reduced SST and of reduced thermocline depth (first row left panel in Figs. 10 and 11). The Z20 anomaly has the characteristic pattern of boundary propagation of coastal Kelvin waves and the reflection of low-latitude Rossby waves triggered by the arrival of an anomalous easterly equatorial wind-provoked upwelling equatorial Kelvin wave (a response noted in sea level observations by Clarke and Liu 1994). The cold SST anomaly 
associated with the Z20 anomaly then reinforces the lack of convection over the region, and its atmospheric response, strengthening the upwelling-favorable equatorial winds $-\mathrm{a}$ wind-thermocline-SST positive feedback.

The Z20 anomaly pattern propagates westward as Rossby waves with higher phase speeds closer to the equator. The anomalies grow through the late Indian monsoon season (AugustSeptember, second row of Figs. 10 and 11), with a reinforcement of the oceanic and atmospheric anomalies described above. In addition to provoking upwelling equatorial Kelvin waves due to their easterly component, the anomalous winds drive an Ekman pumping that extends across the Indian basin, downwelling on both sides of the equator (not shown), but stronger to the south due to the anticyclonic nature of the wind anomalies there. The deepening thermocline response can be seen in the western and particularly in the southwestern tropical Indian Ocean away from the equator, while in the east the upwelling signal from the equatorial and coastal Kelvin waves and reflected Rossby waves dominates. The locally-forced deepened thermocline also propagates westward as a Rossby wave (Xie et al. 2002). The oceanic anomalies evolve in a manner similar to those in the forced ocean simulations (Murtugudde et al., 2000 and Vinayachandran et al., 2002), through this mix of locally and remotely forced influences (also Rao et al., 2002 and Feng and Meyers, 2003). The WTIO thermocline away from the equator continues to deepen through and past the peak of anomalies in the SETIO, though the associated SST response is quite mild in both simulations (left panels of Figs. 10 and 11).

At the peak of the IOZM, which in the model occurs about one month later (November) than in reality, the anomaly patterns described above are at their most intense (third row of Figs. 10 and 11). On the oceanic side, the thin thermocline and associated cold SST anomalies have propagated as coastal Kelvin waves far into the Bay of Bengal and along the Indonesian coast, and communicate far into the interior in near-equatorial regions via Rossby wave propagation. The negative precipitation anomaly has spread to include the entire near-equatorial region.

There is a strong meridional component to the surface wind anomalies in the ETIO, visible throughout the IOZM (center column of Figs. 10 and 11). In the early part of the IOZM this represents an early northward penetration in the seasonal cycle of the southern hemisphere 
southeasterly trade winds, while later (August-September) it can be interpreted as an intensification of the surface winds associated with the monsoon. In the model climatological OctoberNovember, the absolute cross-equatorial winds are quite weak, since the centers of monsoon convection over India and southeastern Asia have disappeared. While this remains the case in the IOZM composite, the lack of rain over the equatorial zone allows a continued northward penetration of the southern hemisphere trades at the surface, into the zone of weak climatological convection still remaining over the Bay of Bengal.

The first significant difference between the composites comes in October-November in the atmosphere. The REF IOZM surface and upper-level winds over the eastern equatorial Indian Ocean indicate a weaker Walker circulation than in the noENSO IOZM, a signature of the El Niño events present in the REF simulation. The ocean anomalies associated with the IOZM remain indistinguishable between the two simulations.

In December-January, the model climatological winds along the coast of Sumatra have reversed sign and are downwelling-favorable, as the main center of convection has shifted south and eastwards during the development of the Australian Monsoon. This deepens the thermocline (not shown), perhaps contributed to by downwelling equatorial Kelvin waves triggered in the western basin (Gualdi et al. 2003b). The deepened thermocline interrupts the Bjerknes feedback and brings the end of the IOZM. The thin thermocline anomalies begin to propagate westward offshore of Sumatra (last row in Figs. 10 and 11). A weak zonal gradient in precipitation anomaly remains, with an increase in the rainfall northeast of Madagascar and a remaining lack of precipitation in the eastern equatorial Indian Ocean. At this time, the two IOZM simulations (REF and noENSO) begin to diverge, with significant differences over the Maritime Continent and in the equatorial Pacific, the signature of the peak of the El Niño events present in REF and absent in noENSO.

\section{b. IOZM atmosphere-ocean feedbacks active in the model}

Li et al. (2003) suggest that there are two positive feedbacks involved in the IOZM, one being the Bjerknes-type wind-thermocline-SST feedback described above, the other being a seasonally positive feedback between the wind, evaporation, and SST. The seasonal cycle of wind along the Sumatra coast (Fig. 2) means that during the boreal summer and fall, wind 
anomalies associated with the IOZM add to the total wind speed, while in other seasons, they reduce it. One factor in the latent heat loss from the ocean is wind speed, so enhanced wind speeds over the Sumatra coastal region could further reduce SST, positively feeding back into the precipitation and associated wind anomaly patterns during boreal summer and fall.

These two feedbacks are diagnosed in the model with simple scatter plots relating key indices. For the Bjerknes-type feedback (Fig. 12), each of the three pairs of relevant indices (equatorial wind with Sumatra Z20, Sumatra Z20 with Sumatra SST, and Sumatra SST with equatorial wind) show fairly tight positive relationships, confirming the active role of the wind-thermocline-SST feedback. The strongest deviations come during the SON IOZM peak. The locally-forced upwelling wind and Sumatra Z20 do not have a very clear relationship (Fig. 12 lower left). Therefore the atmospheric response of the zonal equatorial winds and the ocean dynamical response that brings this upwelling signal from the equator to the Sumatra coast as equatorial and coastal Kelvin waves are more important in the model than locally-driven upwelling (consistent with Murtugudde et al., 2000).

On the other hand, the suggested positive WES feedback along the Sumatra coast does not exist in the model. While a generally positive relationship between wind speed and latent heat loss exists in the boreal winter and spring seasons (Fig. 13, negative half of first panel), it is not very clear in boreal summer and fall (positive half), during the IOZM. The strongest latent heat losses are in fact not associated with colder SSTs, but with the warmest (middle panel of Fig. 13). Instead of the latent heat loss controlling the SST, the SST controls the latent heat loss, particularly during the IOZM. The second major variable other than wind speed in the latent heat flux is the difference between the specific and saturation specific humidity. The relationship between the modeled SST and air temperature is very tightly correlated. When air temperatures are low the saturation specific humidity is reduced, the relative humidity increased towards saturation, and as a consequence, the latent heat flux is limited.

The regions of SST cooling during the growth of the IOZM are in fact associated with positive net air-sea heat fluxes due to the cold SSTs and an increase in solar radiation, a damping negative feedback. 


\section{IOZM triggers and the link with the Pacific}

The largest differences revealed by the statistical test between the IOZM composites from the two simulations occur in the triggering stage, in April-May, and after the peak of the IOZM in December-January.

\section{a. A meridional trigger in the ENSO-suppressed simulation}

The meridional Hadley-type anomaly described below that appears as the trigger for the IOZM in the noENSO simulation is a coherent signal in the composite, and therefore the common triggering mechanism for all IOZM events in this simulation without the influence of ENSO, which make up 29 of the 200 years.

The first significant anomalies in composite event arrive in the Indian Ocean in February and March and establish cooler SSTs in the SETIO region (Fig. 14 first row). The late Australian monsoon surface circulation is reinforced, with a low pressure anomaly off the northwestern Australian coast, and a high pressure anomaly centered further west over the south central Indian Ocean, a reinforcement of the Mascarene high. These are accompanied by anomalous winds that add to the mean, southerly over the south central Indian Ocean and northwesterly along the Sumatra Coast and further west near the equator. These winds follow strengthened convection and rainfall in the southern hemisphere, in February in a zonal region centered over $10^{\circ} \mathrm{S}$ extending from the central to the eastern Indian Ocean, in March spanning northwestern Australia and far eastern Indonesia. The increased cloudiness associated with the increased rainfall and an increased latent heat loss due to stronger winds reduce the net air-sea heat flux (not shown). The result is that by April, the SST in the SETIO region is anomalously cold.

The colder SSTs in the SETIO contribute to a reduction in the convection and rainfall in this region during the late spring. In the mean model climatology the SETIO rainfall increases from April through June, before decreasing as the center of convection shifts northward with the development of the Asian monsoon. Responding to the SETIO cold anomaly and therefore an increase in the meridional surface temperature between the SETIO and regions to its north, an early northward shift in convection occurs, accompanied by a northward shift in the southeasterly trades (seen as anomalous southeasterlies south of the equator in Fig. 14, second row). 
This anomalous Hadley circulation is apparent in April-May over the central and eastern tropical Indian Ocean, with an excess of precipitation on and north of the equator and a lack of precipitation in the SETIO, extending zonally both west and east. The surface winds have a strong southerly component, while the $200 \mathrm{mb}$ winds have a strong northerly component. This cell represents an early strengthening of the eastern portion of the climatological Hadley cell of the Asian monsoon circulation, which has begun to penetrate north of the equator, bringing the southern hemisphere southeasterly trades to the equator. It can also be thought of as a quickerthan-normal seasonal change between a strong Australian and a strong eastern portion of the Asian monsoon circulations.

The consequence of this anomalous Hadley cell for the Indian Ocean is that the conditions for the positive growth of the IOZM anomaly have been set up - the early northward penetration of the southeasterly trades brings an upwelling easterly wind component to the equator, and the reduced convection over the SETIO is accompanied by a reduction in atmospheric column heating. This leads to the westward-displaced Matsuno-Gill anticyclonic surface wind response, and a thermocline and SST response to these anomalous winds that reinforces the drop in SST, further reducing the precipitation - the positive feedback described in Section 3.

There are no driving anomalies in or over the Pacific Ocean during the triggering phase in the noENSO IOZM composite. Later, since there remains a thermodynamic coupling over the constrained tropical Pacific, there is an oceanic response under the zone of increased convection and rainfall in the South China Sea and northwestern tropical Pacific, a reduction in the surface salinity and in the surface temperature (top left panel of Fig. 11, salinity not shown).

\section{b. Two types of triggers in the reference simulation}

A separation of the REF IOZM cases into two groups, those that occur with El Niño events (using the index described in Guilyardi et al. 2003) and the rest, reveals two mechanisms in boreal spring that can trigger an IOZM event. The same statistical test, placing the actual difference between the two groups in an Monte Carlo-derived estimate of the probability density function of the difference, was used to determine the significant differences between the REF IOZM/El Niño and REF IOZM/no El Niño composites. 
The subset of REF IOZM/no El Niño events, 30 of the 37 REF IOZM, shares many features of the noENSO simulation IOZM composite (compare Fig. 15 and Fig. 14), including the reinforcement of the seasonal circulation in the southeastern Indian Ocean in February-March, accompanied by an excess in precipitation centered over $10^{\circ} \mathrm{S}$. A setup of anomalously cold SSTs in the SETIO region following the strengthened Australian monsoon circulation contributes to a later lack in April-May rainfall, accompanied by an increase in the rainfall further north. There is an anomalous Hadley circulation over the eastern equatorial Indian Ocean in April-May, with zones of southerly cross-equatorial flow at the surface and the return northerly flow at $200 \mathrm{mb}$ (Fig. 15 second row). As before, the early northward penetration across the equator of the southeasterly trades and lack of SETIO rainfall provide the triggering anomalies that lead to the positive feedback of IOZM growth. As in the composite noENSO IOZM, there is no involvement of anomalies in the Pacific Ocean, so processes in and over the Pacific Ocean do not appear to contribute to this type of IOZM development.

Another way in which the IOZM is triggered in the REF simulation, clearly absent in noENSO, is associated with the developing phase of El Niño anomalies in the Pacific. The evolution of the subset of REF IOZM events coincident with a full El Niño, 7 of the 37 REF IOZM, is shown in Fig. 16. On the oceanic side, the thin thermocline anomaly appears early and is well-developed by April-May. It responds to an equatorial easterly wind anomaly in the eastern Indian Ocean that is more zonal than those found in Indian-only IOZM events. This zonal wind anomaly develops as the atmosphere responds to an eastward shift in the center of convection with the developing El Niño, which over the Maritime Continent draws the equatorial surface winds towards it (second row of Fig. 16, compare with second row of Fig. 15). Centered over the SETIO and crossing the equator is a region of reduced precipitation, accompanied by the now-familiar Matsuno-Gill anticyclonic response and the upwelling-favorable easterly wind anomaly on the equator, triggering the early growth of the IOZM. At upper levels the anomalous winds have a strong easterly component linking the regions of increase and decrease in precipitation. The anomalies over the Maritime Continent describe a largely zonal anomaly of the boreal spring Walker circulation, which through the reduction in convection over the ETIO leads to the IOZM event. The IOZM is also clearly seen in composites of El 
Niño events in REF, evolving as described above, confirmation of the robust relationship between the two. This triggering mechanism has been discussed by Yu and Rienecker (2000), Annamalai et al. (2003), and Gualdi et al. (2003b).

This link to a Walker-type IOZM triggering mechanism in April-May, connected to a developing El Niño, allows an understanding of the statistically significant but only moderately strong correlation between ENSO and the IOZM seen in the model (right two panels, Fig. 6). In REF, there are two triggering paths that lead to the initial growth of the IOZM. One subset of IOZM events is connected to the changes in convection and the Walker circulation due to a developing El Niño event in the boreal spring (upper path in the schematic Fig. 17). The direct change to the equatorial Walker circulation leads to a dynamic atmospheric response to the lack in heating over the SETIO (central schematic in Fig. 17) and a dynamic oceanic response, and finally to the coupled growth of the IOZM. However, in the model as in the climatological record, IOZM events can exist when the Pacific not in an El Niño state. In the model the trigger for all the noENSO IOZM events and all of the REF IOZM events not associated with an El Niño has a meridional character associated with an anomalous April-May ETIO Hadley circulation, with increased precipitation on and north of the equator and reduced precipitation over the SETIO. This grows out of cooler SETIO SSTs that came from a reinforcement of the seasonal wind patterns in February-March (lower path in Fig. 17). The result, as in the Walker-type trigger, is a dynamical ocean response to anomalous equatorial winds that leads to the coupled growth of the IOZM.

\section{Discussion: model dynamics and the observed climatological system}

Can the identified dynamics of this Hadley-type triggering mode in the coupled model be found in climatological analyses? How might differences between the mean observed and model climatologies mentioned in Section 2c color the conclusions?

In the modern climatological record of the last 50 years, there are three years in which the Indian Ocean has developed a strong IOZM with the Pacific Ocean not in an El Niño state, 1961, 1967, and 1994, and three $(1972,1982,1997)$ that have developed with an El Niño (Saji and Yamagata, 2003b). 
Taking first the years of IOZM associated with a neutral ENSO phase, our first question is whether they exhibit the same anomalous Hadley cell circulation in the triggering phase of the IOZM as seen in the model. In 1994, the early evolution of anomalies in the Indian Ocean has a number of similarities with the model noENSO composite IOZM. This evolution is shown from oceanic and atmospheric reanalyses in Fig. 18. In February-March, a reinforcement of the mean surface circulation and increased precipitation over the ETIO, associated with a reinforced Mascarene high in the south central Indian Ocean and reinforced winds along the Sumatra coast, overlies a region of anomalously cold SSTs. Anomalously strong latent heat losses due to the strong winds (seen in the SOC climatology, not shown) contribute to the cold SSTs. Associated with the cooler SSTs, precipitation over a zonal swath in the eastern Indian ocean centered at $10^{\circ} \mathrm{S}$ is reduced in April-May, and is stronger further north, allowing an early northward penetration of the surface southeasterly trades. This situation is very similar to that found in April-May in the noENSO IOZM composite (Fig. 11). In June-July a strong lack of precipitation over the SETIO, compensated in this case by a strong increase in precipitation over the South China Sea and the Philippines, sets up a situation with a broad southerly surface cross-equatorial flow and upper level northerly flow over the Maritime Continent, an anomalous Hadley circulation similar to that seen in the model, though greater in latitudinal extent. The surface expression of this Hadley circulation, the northward penetration of the southeasterly trades, has an easterly upwelling component on the equator, and a thermocline and SST response are visible in April-May, stronger in June-July. This reinforces the lack of precipitation over the SETIO, yielding a Matsuno-Gill atmospheric response to this lack of heating, and the IOZM has been triggered, growing through its peak in October. The 1994 IOZM differs from the noENSO model run composite in August-September, where there is a zonal Walker character to the anomalous atmospheric circulation, associated with a warming of the central Pacific and an eastward shift of the Pacific Warm Pool and precipitation (Fig. 18 fourth row). This Walker anomaly may contribute to the strength of the IOZM. The triggering phase from February through May remains, however, similar to the Hadley-type trigger described in the model composites. 
In 1997, a very strong El Niño event occurred along with an IOZM event (Fig. 19). The eastward shift in the Pacific Warm pool and center of convection and rainfall begins early, already evident in February-March. In the model, this eastward shift, taking place in AprilMay (Fig. 16), was not as far east, and the immediate compensation was a reduction in precipitation over the eastern equatorial Indian Ocean. In April-May 1997 the increase in convection and precipitation has reached the dateline, and the compensating decrease is in the far western Pacific Ocean. By June-July there is a strong lack of precipitation over the SETIO region, accompanied by the Matsuno-Gill anticyclonic atmospheric response, and a dynamical ocean response to the upwelling-favorable winds - and the IOZM has been triggered. These anomalous patterns intensify through the peak of the IOZM in October-November 1997 (Yu and Rienecker 2000). While the details of the IOZM in 1997 differ from the model IOZM/El Niño composite, the major IOZM trigger, the eastward April-May shift in convection associated with the developing El Niño, is consistent.

Not all climatological IOZMs are triggered by the two paths identified in the model runs, the 1961 IOZM evolved differently. The All-India Monsoon Rainfall index (Parthasarathy et al. 1995) identifies 1961 as the strongest monsoon on record. The Northeast Monsoon season ended unusually early, in February-March an early northward movement of the southern southeasterly trades had occured. By April-May the Southwest Monsoon flow had begun, with strong northward cross-equatorial flow and a Findlater Jet, and strong precipitation anomalies over India and the eastern coast of the Bay of Bengal. This early monsoon circulation impeded the usual development of westerly equatorial winds in the Indian Ocean, and thus the spring equatorial oceanic Wyrtki jet, yielding a shallower thermocline and cooler SST in the ETIO. This distortion of the monsoonal circulation led to a reduction in precipitation over the Maritime Continent, perhaps responding to the cool SSTs in the eastern Indian Ocean. The 1961 IOZM was thus triggered by mechanisms rather different than those modeled here- one conclusion is that the model does not capture all the modes of variability exhibited by the natural system.

The coupled model has a bias towards a shallow boreal fall ETIO thermocline and high SST variability, for the reasons outlined in Section 2. The recent climate record suggests, how- 
ever, that IOZM events in the absence of El Niño, similar to those modeled, can and have occured. One question relevant to predictability that might be addressed by future research is whether threshold levels for anomalies necessary to trigger the IOZM can be identified.

\section{Summary}

This paper has addressed the debate over the dynamical links between the IOZM and ENSO, essentially asking the question: can the IOZM exist without ENSO? What are the triggers for the IOZM? What dynamical processes lead to the statistically significant but not inevitable phase-locking between El Niño and IOZM events?

We have used two runs of a coupled model, one freely evolving and the other regionally constrained with model seasonal mean wind stresses to suppress ENSO, to examine the dynamics of the IOZM. We find that the IOZM can exist in the absence of ENSO, and that it evolves with virtually the same coupled dynamics as IOZM events in the reference simulation. In the model, the wind-thermocline-SST Bjerknes positive feedback is the key dynamical mechanism at work in IOZM growth, with the propagation of equatorial upwelling by oceanic Kelvin and Rossby waves more important than locally wind-driven upwelling along the Sumatra coast. The surface heat flux, driven by an increase in solar radiation as well as decrease in latent heat loss and longwave radiation, acts as a negative damping feedback on IOZM growth.

There are two triggering events for the IOZM. The first is the only way in which IOZM events are triggered in the noENSO simulation, and appears in boreal spring as an anomalous meridional Hadley cell with as surface expression an early northward penetration across the equator of the southeasterly trades in the eastern tropical Indian Ocean. This Hadley cell responds to cooler SETIO SSTs left by anomalously strong seasonal winds in the late austral summer, consequently shifting the center of atmospheric convection northwards.

These anomalous winds have an easterly component on the equator, provoking upwelling Kelvin waves which rapidly reach the Sumatra coast and spread north and south as coastal Kelvin waves, reducing the depth of the thermocline and decreasing SSTs on the equator and the eastern boundaries, and propagating westward into the interior as Rossby waves. The 
reduction in SSTs in the SETIO further inhibits convection and precipitation, leading to a dynamical Matsuno-Gill atmospheric response with a westward-displaced anticyclonic wind anomaly, including an easterly equatorial component over the Indian Ocean, and the IOZM undergoes a coupled growth. The early evolution described by this model-simulated Hadley cell trigger is similar to the situation in 1994 from February through May, one of few events in the recent climatological record in which an IOZM event evolved without the concurrent development of El Niño.

The second triggering mechanism for the IOZM only appears in the reference simulation including ENSO variability, and appears in boreal spring (April-May) as an anomalous zonal Walker cell connecting the eastern tropical Indian Ocean and the Pacific Warm Pool region. It is associated with the developing El Niño, which brings an eastward shift of the convection and precipitation in the western tropical Pacific Ocean, driving an anomalous subsidence and lack of precipitation further west over the SETIO. The lack of precipitation over the SETIO is then accompanied by the dynamical Matsuno-Gill atmospheric response. This second trigger then leads to the same coupled dynamical response that is the early growth of the IOZM as the first.

The presence of this trigger connected to the development of El Niño, already described by Yu and Rienecker (2000), Annamalai et al. (2003) and Gualdi et al. (2003), explains the phaselocking often seen between Indian Ocean and Pacific Ocean interannual variability, and significant seasonally-stratified anticorrelation seen between SETIO and Niño3.4 SST anomalies in both the climatological record and the coupled model. The presence of the first, Hadley cell anomaly triggering mechanism, allows us to understand the existence of IOZM variability independent of the Pacific ENSO state.

One major question not addressed by this work is what causes the reinforced seasonal winds and eastward Mascarene high shift during the late austral summer, the first significant anomalies in the Hadley-cell IOZM trigger. These anomalies bear a strong resemblance to the subtropical dipole described by Behera and Yamagata (2001). Terray et al. (2003, 2004b) found that the same shift in the Mascarene high, associated with underlying SST anomalies, persisted and weakened the following late Indian summer monsoon Hadley circulation, being 
therefore a consistent predictor of monsoon strength. It has been suggested that such anomalies are related to the Antarctic circumpolar wave (Peterson and White 1998; Fachereau et al. 2003), or to the Pacific ENSO state (Kidson and Renwick 2002). Meehl and Arblaster (2002) reported that the strength of the Australian monsoon circulation was tied to that of the preceding Indian summer monsoon, and viewed the entire Indo-Pacific tropical system, including the monsoonal circulations, ENSO, and the equatorial Indian dipole, as part of a coupled system linked by the Walker circulations, with a boreal spring state transition that sets the stage for the phase of the tropical biennial oscillation. These modes of variability appear interrelated to various degrees, and their connections merit further study. Isolation of local mechanisms in coupled models, the approach used here to study the IOZM, may be one fruitful avenue of further research.

Acknowledgments. The NCAR/NCEP reanalysis data was provided through the NOAA Climate Center (http://www.cdc.noaa.gov), and SODA analysis data from the IRI data library server (http://iridl.columbia.edu). Simulations were run on the SINTEX NEC SX-4 and at the French Institute for Development and Resources in Scientific Computing (IDRIS). Graphics prepared using the SAXO package of Sébastien Masson. The computer support of Edmée Durand and Robinson Hordoir are gratefully acknowledged. Discussions with Julia Slingo, JP Boulanger, Jérôme Vialard, Gurvan Madec, Matthieu Lengaigne, Antonio Navarra, and Chris Bretherton contributed to the evolution of this work. ASF was funded by the Scientific Mission of the French Embassy in America, and the Swiss Federal Office of Education and Science (BBW/OFES).

\section{REFERENCES}

AchutaRao, K., and K. R. Sperber, 2002: Simulation of the El Niño Southern Oscillation: Results from the Coupled Model Intercomparison Project. Climate Dyn., 29, 191-209.

Allan, R., D. Chambers, W. Drosdowsky, H. Hendon, M. Latif, N. Nicholls, I. Smith, R. Stone, and Y. M. Tourre, 2001: Is there an Indian Ocean dipole, and is it independent of the El Niño - Southern Oscillation. CLIVAR Exchanges, 6, Num. 3, 18-21.

Annamalai, H., R. Murtugudde, J. Potemra, S. P. Xie, P. Liu, and B. Wang, 2003: Coupled dynamics over the Indian Ocean: spring initiation of the Zonal Mode. Deep-Sea Res. II, 50, 2305-2330.

Ashok, K., Z. Guan, and T. Yamagata, 2001: Impact of the Indian Ocean Dipole on the relationship between the Indian monsoon rainfall and ENSO, Geophys. Res. Lett., 28, 44994502.

Baquero-Bernal, A., M. Latif, and S. Legutke, 2002: On dipolelike variability of sea surface temperature in the tropical Indian Ocean. J. Clim., 15, 1358-1368.

Behera, S. K. and T. Yamagata, 2001: Subtropical SST dipole events in the southern Indian Ocean. Geophys. Res. Lett., 28, 327-330.

-, S. A. Rao, H. N. Saji, and T. Yamagata, 2003: Comments on "A Cautionary Note on the 
Interpretation of EOFs". J. Clim., 16, 1087-1093.

Bjerknes, J., 1969: Atmospheric teleconnections from the equatorial Pacific. Mon. Wea. Rev., 97, 163-172.

Black, E., J. Slingo, and K. R. Sperber, 2003: An observational study of the relationship between excessively strong short rains in coastal East Africa and Indian Ocean SST, Mon. Wea. Rev., 131, 74-94.

Carton, J. A., G. Chepurin, X. Cao, and B. Giese, 2000: A simple ocean data assimilation analysis of the global upper ocean 1950-95. Part I: Methodology. J. Phys. Oceanogr., 30, 294-309.

Chambers, D. P., B. D. Tapley, and R. H. Stewart, 1999: Anomalous warming in the Indian Ocean coincident with El Niño. J. Geophys. Res., 104, 3035-3047.

Clarke, A. J. and X. Liu, 1994: Interannual sea level in the northern and eastern Indian Ocean. J. Phys. Oceanogr., 24, 1224-1235.

Clark, C.O., P.J. Webster, and J.E. Cole, 2003: Interdecadal variability of the relationship between the Indian Ocean Zonal Mode and East African coastal rainfall anomalies, J. Clim., 16, 548-554.

Dommenget, D. and M. Latif, 2002: A cautionary note on the interpretation of EOFs. J. Clim., 15, 216-225.

Elliott, J. R., S. P. Jewson, and R. T. Sutton, 2001: The impact of the 1997/98 El Niño event on the Atlantic Ocean. J. Clim., 14, 1069-1077.

Fachereau, N., S. Trzaska, Y. Richard, P. Roucou, and P. Camberlin, 2003: Sea-surface temperature co-variability in the Southern Atlantic and Indian Oceans and its connections with the atmospheric circulation in the Southern Hemisphere. Int. J. Climatol., 23, 663-677.

Frankignoul, C. and K. Hasselman, 1977: Stochastic climate models. Part II. Application to seasurface temperature, temperature anomalies and thermocline variability. Tellus, 29, 289305.

Gill, A., 1980: Some simple solutions for heat induced tropical circulation. Quart. J. Roy. Meteor. Soc., 106, 447-462.

Gualdi, S., A. Navarra, E. Guilyardi, and P. Delecluse, 2003a: The SINTEX coupled GCM. The tropical Indo-Pacific region. Ann. Geophys., 46, 1-26.

-, E. Guilyardi, A. Navarra, S. Masina, and P. Delecluse, 2003b: The interannual variability in the tropical Indian Ocean as simulated by a CGCM. Climate Dyn., 20, 567-582.

Guilyardi, E., P. Delecluse, S. Gualdi, and A. Navarra, 2003: Mechanisms for ENSO phase change in a coupled GCM. J. Clim., 16, 1141-1158.

—, S. Gualdi, J.M. Slingo, A. Navarra, P. Delecluse, J. Cole, G. Madec, M. Roberts, M. Latif, and L. Terray, 2004: Representing El Niño in coupled ocean-atmosphere GCMs: the dominant role of the atmospheric component. J. Clim., in press.

Hasselman, K., 1976: Stochastic climate models. Part 1. Theory. Tellus, 28, 473-485.

Josey, S., E. Kent, and P. Taylor, 1999: New insights into the ocean heat budget closure problem from analysis of the SOC air-sea flux climatology. J. Clim., 12, 2856-2880.

Kajikawa, Y., T. Yasunari, and R. Kawamura, 2003: The Role of the Local Hadley Circulation over the Western Pacific on the Zonally Asymmetric Anomalies over the Indian Ocean. $J$. Met. Soc. Japan, 81, 259-276.

Kalnay, E., and Coauthors, 1996: The NCEP/NCAR 40-Year Reanalysis Project. Bull. Amer. Meteor. Soc., 77, 437-471.

Kidson, J. W. and J. A. Renwick, 2002: The southern hemisphere evolution of ENSO during 1981-99. J. Clim., 15, 847-863.

Lareef, A., A.S. Rao, and T. Yamagata, 2003: Modulation of Sri Lankan Maha rainfall by the Indian Ocean Dipole, Geophys. Res. Lett., 30, DOI: 10.1029/2002GL015639.

Li, T., B. Wang, C.-P. Chang, and Y.S. Zhang, 2003: A Theory for the Indian Ocean Dipole- 
Zonal Mode. J. Atmos. Sci., 60, 2119-2135.

Levitus, S., 1982: Climatological Atlas of the World Ocean. NOAA Prof. Paper 13, 173 pp. and 17 microfiche.

Matsuno, T., 1966: Quasi-geostrophic motions in the equatorial area. J. Met. Soc. Japan, 44, 25-43.

Madec, G., P. Delecluse, M. Imbard, and C. Levy, 1998: OPA 8.1 ocean general circulation model reference manual, Tech. Rep. LODYC/IPSL Note 11, $91 \mathrm{pp}$.

Meehl, G. A. and J. M. Arblaster, 2002: The Tropospheric Biennial Oscillation and AsianAustralian monsoon rainfall. J. Clim., 15, 722-744.

Meyers, G., 1996: Variation of Indonesian throughflow and the El Niño - Southern Oscillation. J. Geophys. Res., 101, 12,255-12,263.

Mitchell, T., cited 2003: Equatorial Pacific zonal wind anomaly index, 1854-1995. [Available online from http://tao.atmos.washington.edu/data_sets/.]

Murtugudde, R., J. P. McCreary, and A. J. Busalacchi, 2000: Oceanic processes associated with anomalous events in the Indian Ocean with relevance to 1997-1998. J. Geophys. Res., 105, 3295-3306.

Parthasarathy, B., A. A. Munot, and D. R. Kothawale, 1995: All-India monthly and seasonal rainfall series: 1871-1993. Theor. and Appl. Climatol., 49, 217-224.

Peterson, R. G. and W. White, 1998: Slow oceanic teleconnections linking the Antarctic Circumpolar Wave with the tropical El Niño-Southern Oscillation. J. Geophys. Res., 103, 24,573-24,583.

Reverdin, G., D. L. Cadet, and D. Gutzler, 1986: Interannual displacements of convection and surface circulation over the equatorial Indian Ocean. Quart. J. Roy. Meteor. Soc., 112, 4367.

Reynolds, R. W., and T. M. Smith, 1994: Improved global sea surface temperature analyses using optimal interpolation. J. Clim., 7, 929-948.

Roeckner, E., and Coauthors, 1996: The atmospheric general circulation model ECHAM-4: model description and simulation of present-day climate. Max-Planck-Institut für Meteorologie Rep. 218, 94 pp.

Saji, N. H., B. N. Goswami, P. N. Vinayachandran, and T. Yamagata, 1999: A dipole mode in the tropical Indian Ocean. Nature, 401, 360-363.

- and T. Yamagata, 2003a: Possible Impacts of Indian Ocean Dipole mode events on global climate, Climate. Res., in press.

- and - , 2003b: Structure of SST and surface wind variability during Indian Ocean Dipole Mode years: COADS observations, J. Clim., 16, 2735-2751.

Terray, P., P. Delecluse, S. Labattu, and L. Terray, 2003: Sea Surface Temperature Associations with the Late Indian Summer Monsoon. Climate Dyn., 21, 593-618.

-, E. Guilyardi, A. S. Fischer, and P. Delecluse, 2004a: Dynamics of Indian Monsoon and ENSO Relationships in the SINTEX Coupled Model. Climate Dyn., in press.

-, S. Dominiak, and P. Delecluse, 2004b: Role of the Southern Indian Ocean in the Transitions of the Monsoon-ENSO System During Recent Decades, Climate Dyn., in press.

Valcke, S., L. Terray, and A. Piacentini, 2000: The OASIS coupler user guide version 2.4. Tech. Rep. TR/CMGC/00-10, CERFACS, 88 pp.

Vinayachandran, P. N., S. Iizuka, and T. Yamagata, 2002: Indian Ocean dipole mode events in an ocean general circulation model. Deep-Sea Res. II, 49, 1573-1596.

Webster, P. J., A. M. Moore, J. P. Loschnigg, and R. R. Leben, 1999: Coupled oceanatmosphere dynamics in the Indian Ocean during 1997-98. Nature, 401, 356-360.

Wyrtki, K., 1973: An equatorial jet in the Indian Ocean. Science, 181, 262-264.

Xie, P. and P. A. Arkin, 1997: Global Precipitation: A 17-year monthly analysis based on gauge observations, satellite estimates and numerical model outputs. Bull. Amer. Meteor. Soc., 78, 
2539-2558.

Xie, S.-P., H. Annamalai, F. A. Schott, and J. P. McCreary, 2002: Structure and mechanisms of south Indian Ocean climate variability. J. Clim., 15, 864-878.

Yamagata, T., S. K. Behera, S. A. Rao, Z. Guan, K. Ashok, and H. N. Saji, 2002: The Indian Ocean dipole: a physical entity. CLIVAR Exchanges, 7, Num. 2, 15-18.

Yu, L. and M. M. Rienecker, 2000: Indian Ocean warming of 1997-1998. J. Geophys. Res., 105, 16,923-16,939. 


\section{FIGURES AND CAPTIONS}
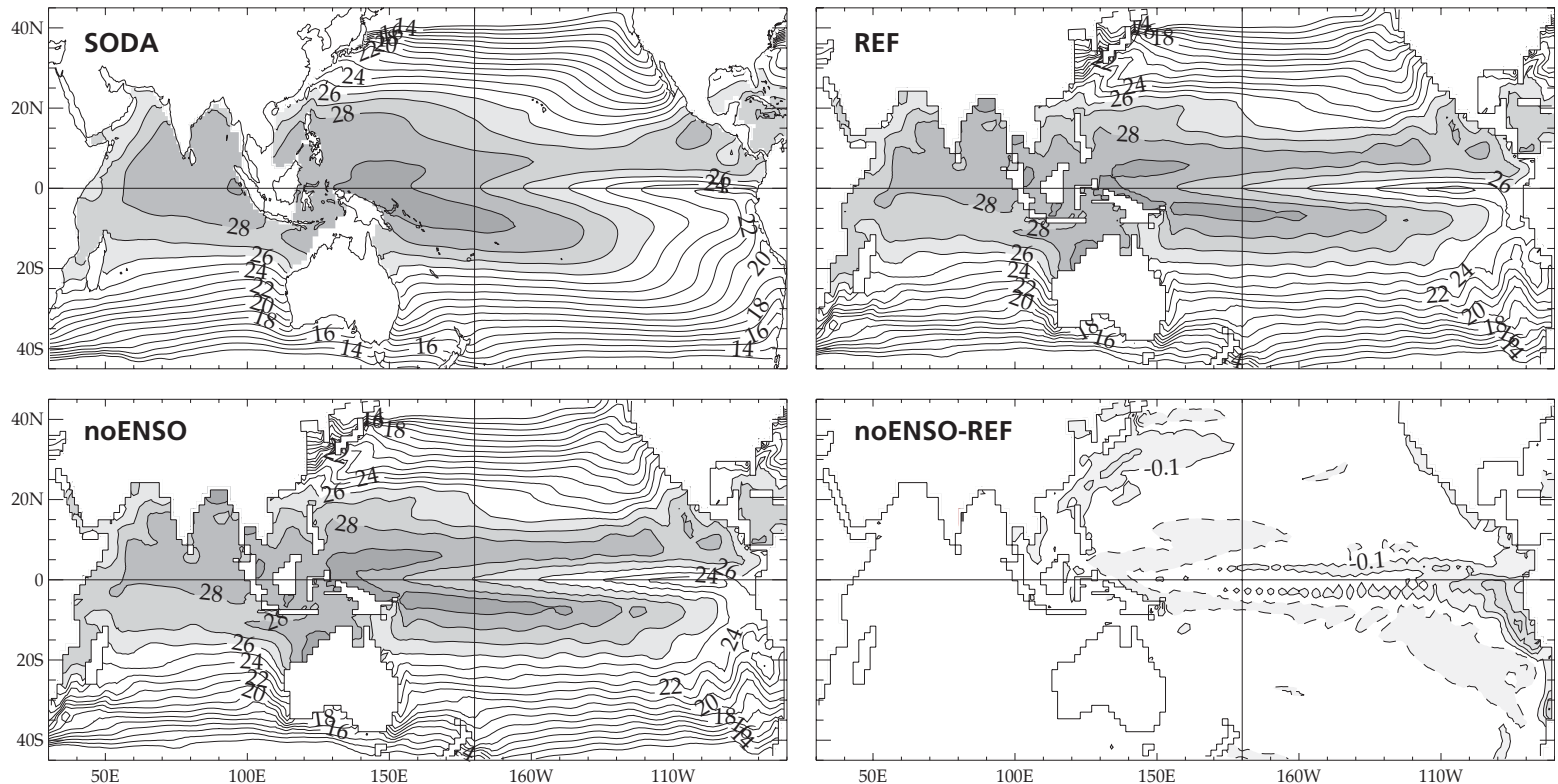

FIG. 1. Comparisons of mean SST for the SODA dataset, the 200-year reference run (REF), the 200-year windstress-constrained run (noENSO), and the difference between noENSO and REF. Mean panels have contour interval of $1^{\circ} \mathrm{C}$ and SST greater than $26^{\circ} \mathrm{C}$ is shaded grey. The difference panel has contour interval of $0.2^{\circ} \mathrm{C}$, negative contours solid line, positive contour dashed line, with a maximum of $0.7^{\circ} \mathrm{C}$ just west of Peru at $12^{\circ} \mathrm{S}$. 

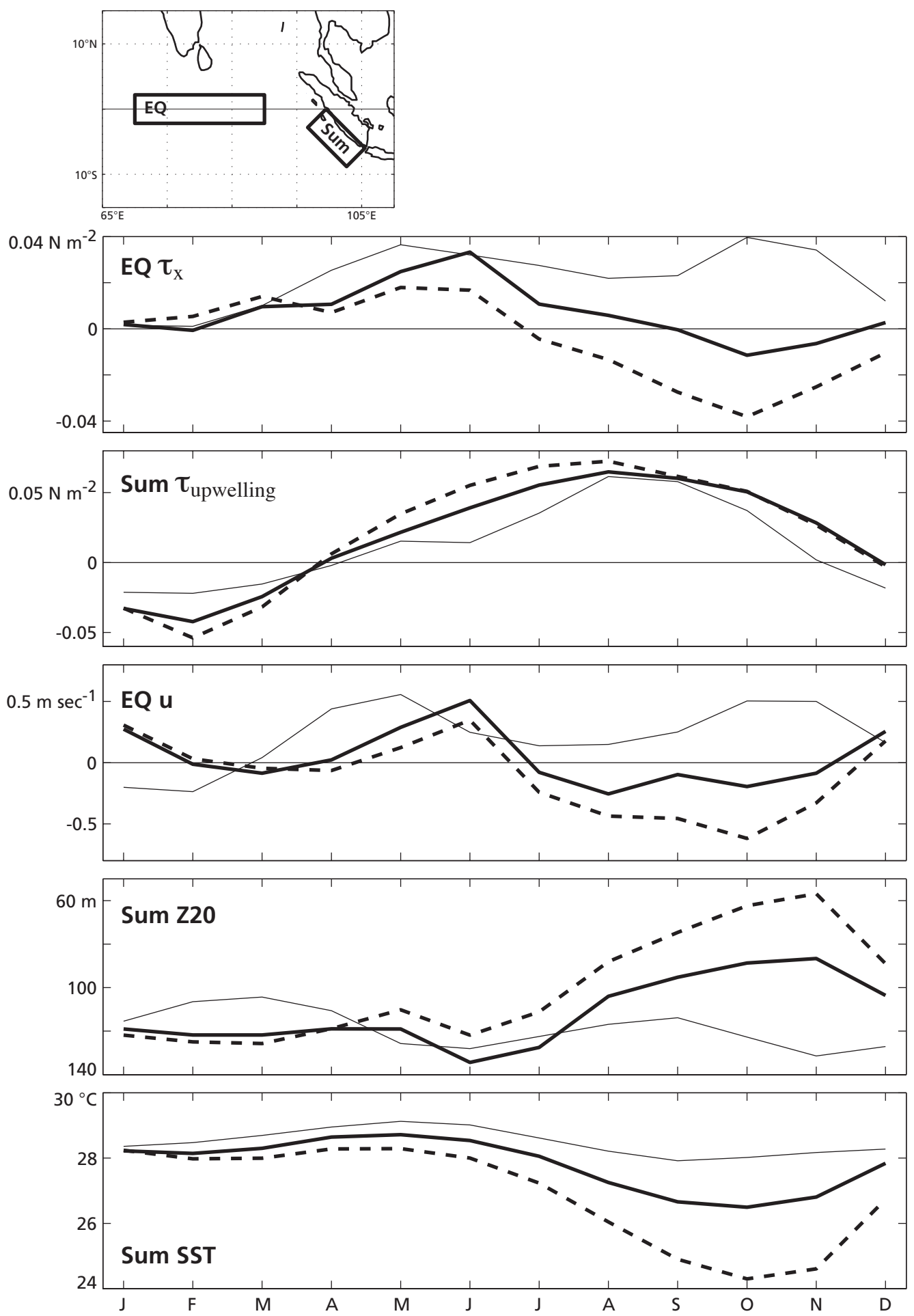

FIG. 2. The time evolution over one year of various indices important to the dynamical evolution of the IOZM, from: mean climatological observations (thin line), the mean seasonal cycle from the REF simulation (thick line), and the composite evolution during an IOZM event from the REF simulation (thick dotted line). For, from top: the zonal wind stress in an equatorial box $\left(70-90^{\circ} \mathrm{E}, 2^{\circ} \mathrm{S}-2^{\circ} \mathrm{N}\right)$, the upwelling (exactly southeasterly) component of the wind stress in the box along the Sumatra coast (on map above, a rectangle $4^{\circ}$ wide and $8.5^{\circ}$ long oriented at an angle of $45^{\circ}$ to the equator), the zonal current in the equatorial box, the depth of the $20^{\circ} \mathrm{C}$ isotherm, and SST, both in the Sumatra box. Climatological wind stress comes from SOC, oceanographic quantities from SODA. Quantities in the Sumatra box were averaged over oceanic grid points. 

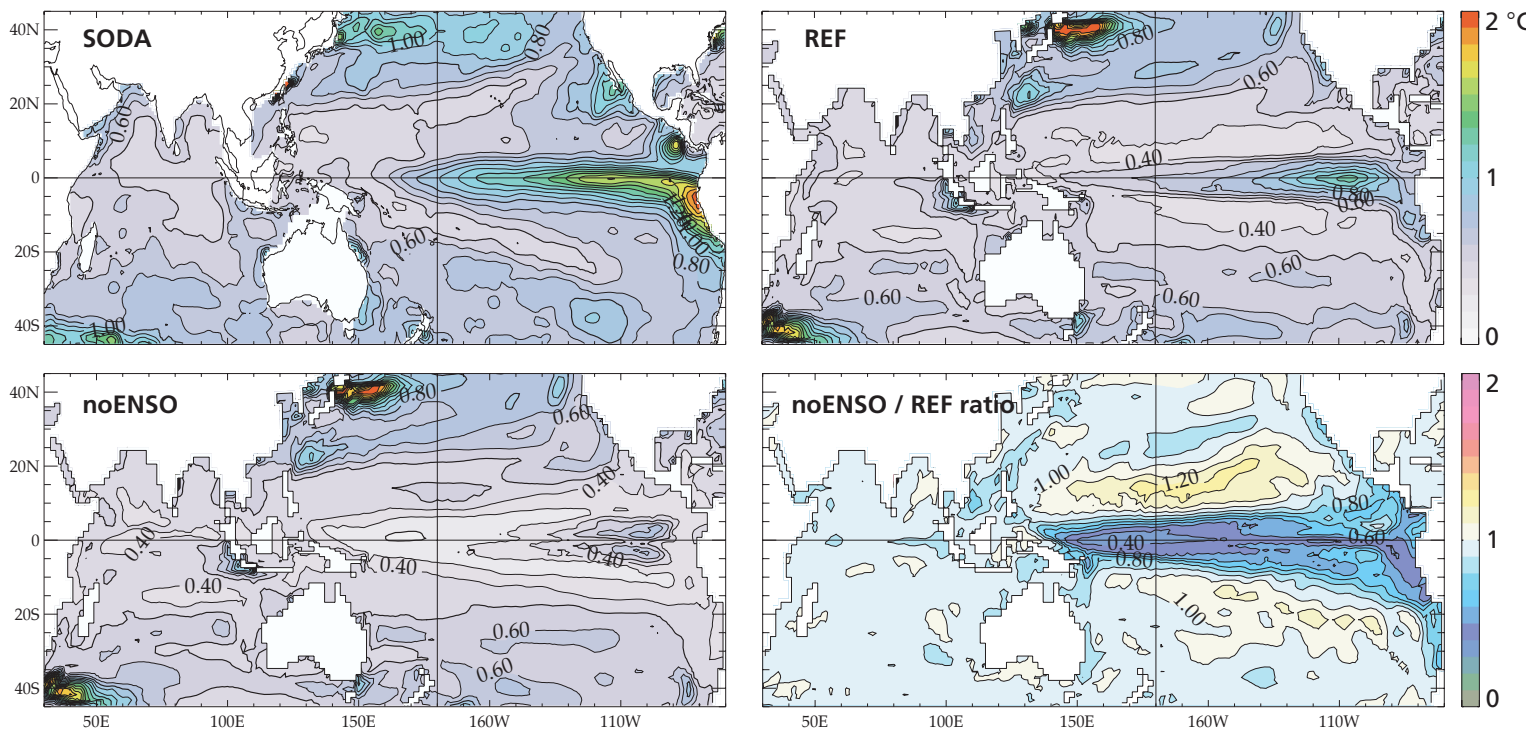

FIG. 3. Comparisons of the interannual variability in SST: standard deviation of the SST with respect to the mean seasonal cycle for the SODA analysis, and the runs REF and noENSO. The ratio of the standard deviations noENSO/REF is shown in the lower right panel.
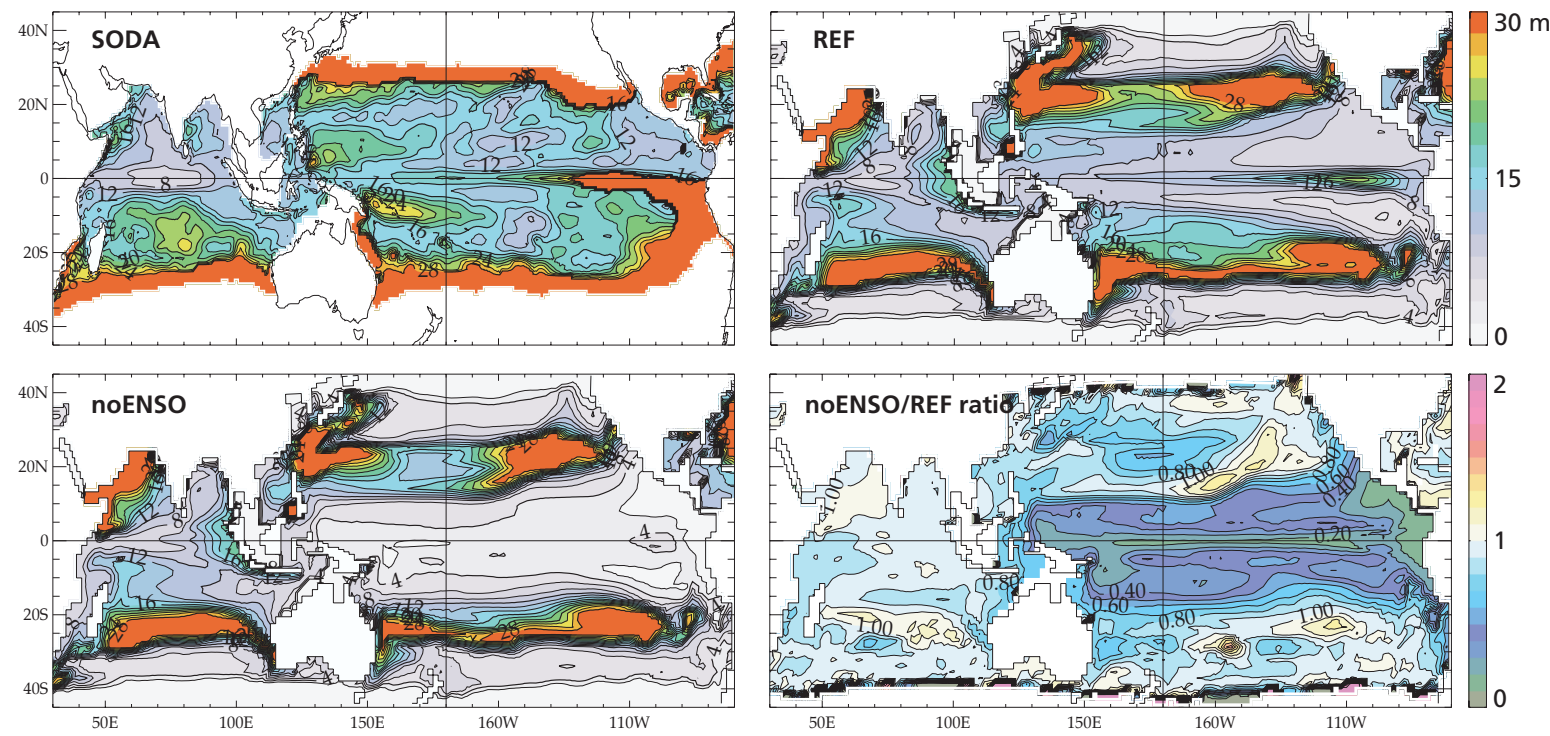

FIG. 4. Comparisons of the interannual variability in $20^{\circ} \mathrm{C}$ isotherm (Z20) depth: standard deviation of Z20 with respect to the mean seasonal cycle, for SODA data, the REF and noENSO simulations, and the ratio noENSO/ REF. 

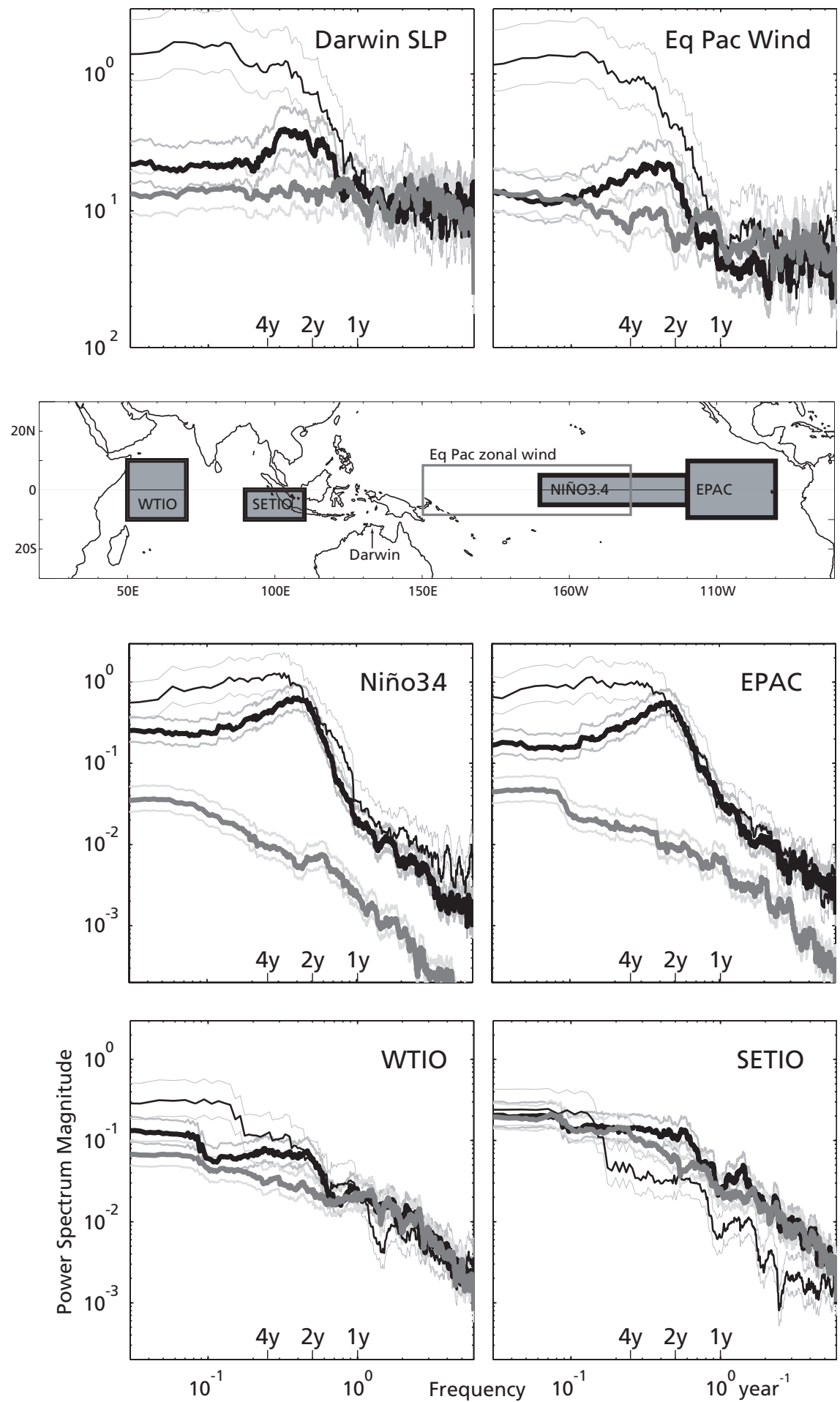

FIG. 5. Power spectra of representative atmospheric (Darwin, Australia sea level pressure and zonal wind in the equatorial Pacific, top 2 panels) and oceanic indices in the Pacific (the Nino3.4 and eastern equatorial Pacific SST anomaly indices, middle 2 panels) and Indian (WTIO and SETIO SST anomalies, bottom 2 panels) oceans, for climatological data (thin black line), and the REF (thick black line), and noENSO (thick grey line) simulations, calculated using the multi-taper method. Pale lines parallel to the main traces indicate the $95 \%$ confidence interval. 


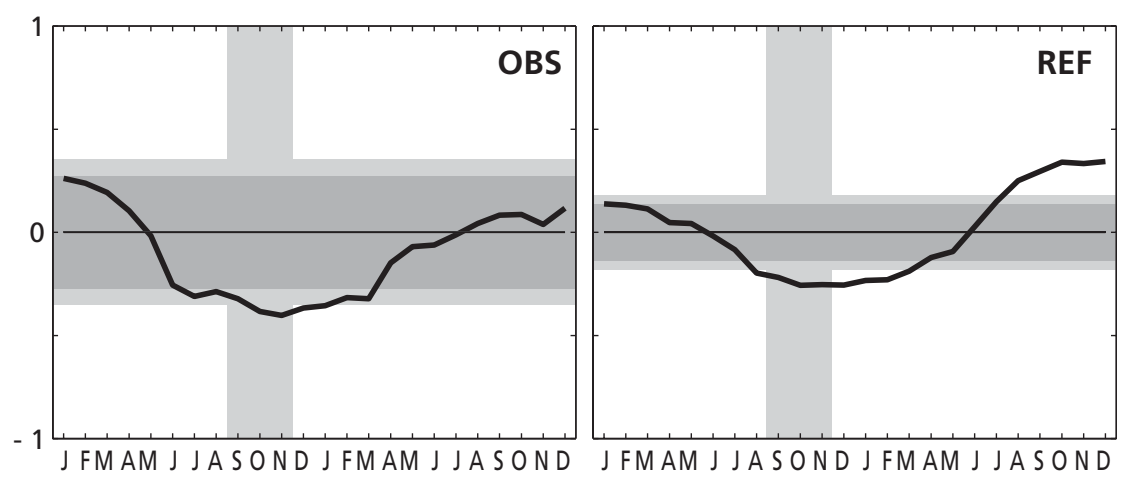

NIÑO 3.4 (monthly) and SETIO (SON)

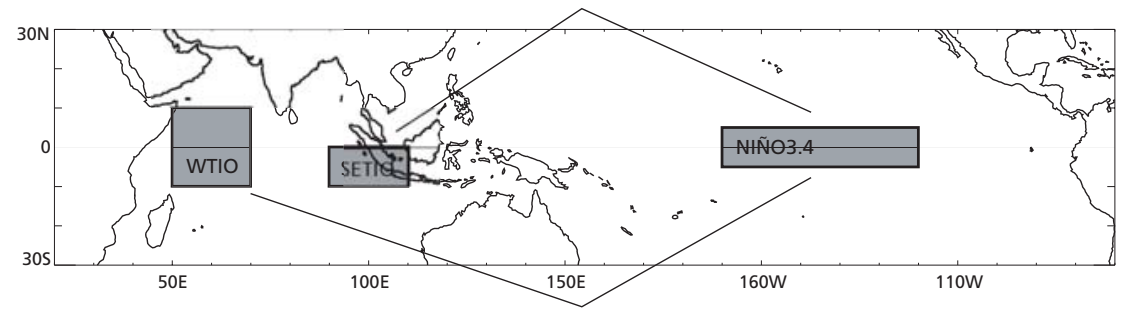

NIÑO 3.4 (monthly) and WTIO (NDJ)

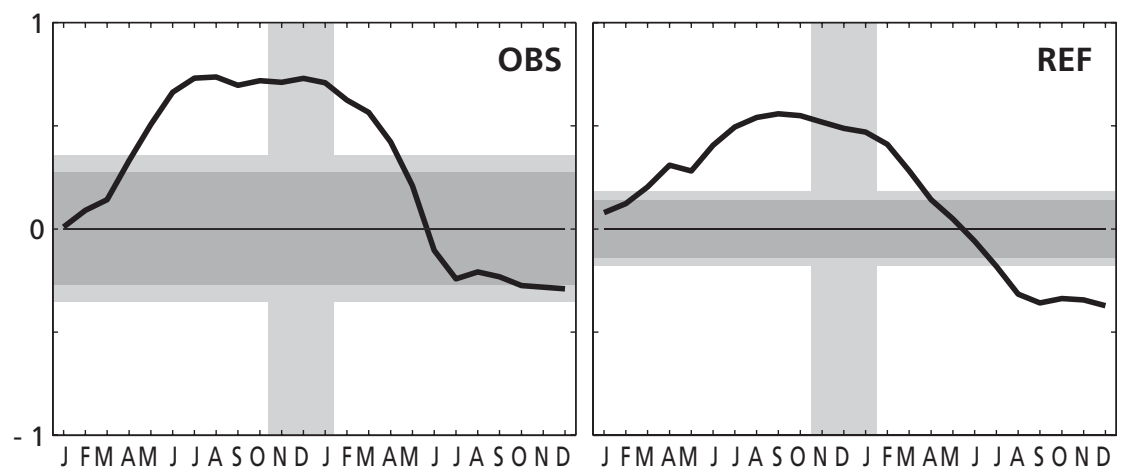

FIG. 6. Lead-lag correlations between seasonal indices of SST anomaly in the SETIO (top panels) and the WTIO (bottom panels) with the monthly Pacific Niño3.4 SST anomaly timeseries, in both observations (OBS, Reynolds and Smith, 1994) and the REF simulation. The dark and light horizontal bands delimit the 95 and $99 \%$ confidence intervals, while the season for the Indian Ocean index (SON for SETIO and NDJ for WTIO, the season of maximum interannual variability) is marked by the vertical band, showing the zero-lag correlation. 


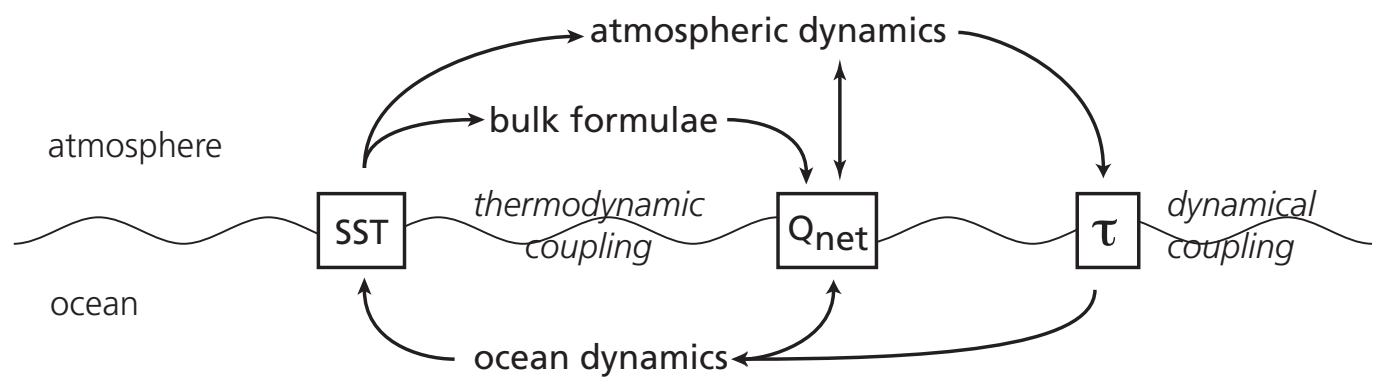

FIG. 7. A schematic of the coupling between the modeled atmosphere and ocean, emphasizing the agents of exchange between the models. The atmosphere sees the ocean SST as a boundary condition, forcing a response in both the net heat flux across the interface (via the bulk formulae) and in the wind produced (through atmospheric dynamics). The ocean sees the net heat flux as well as the wind stress produced by the atmospheric model, and in turn produces an SST field. The boxes mark fields exchanged between components that could be used to constrain the coupled model.

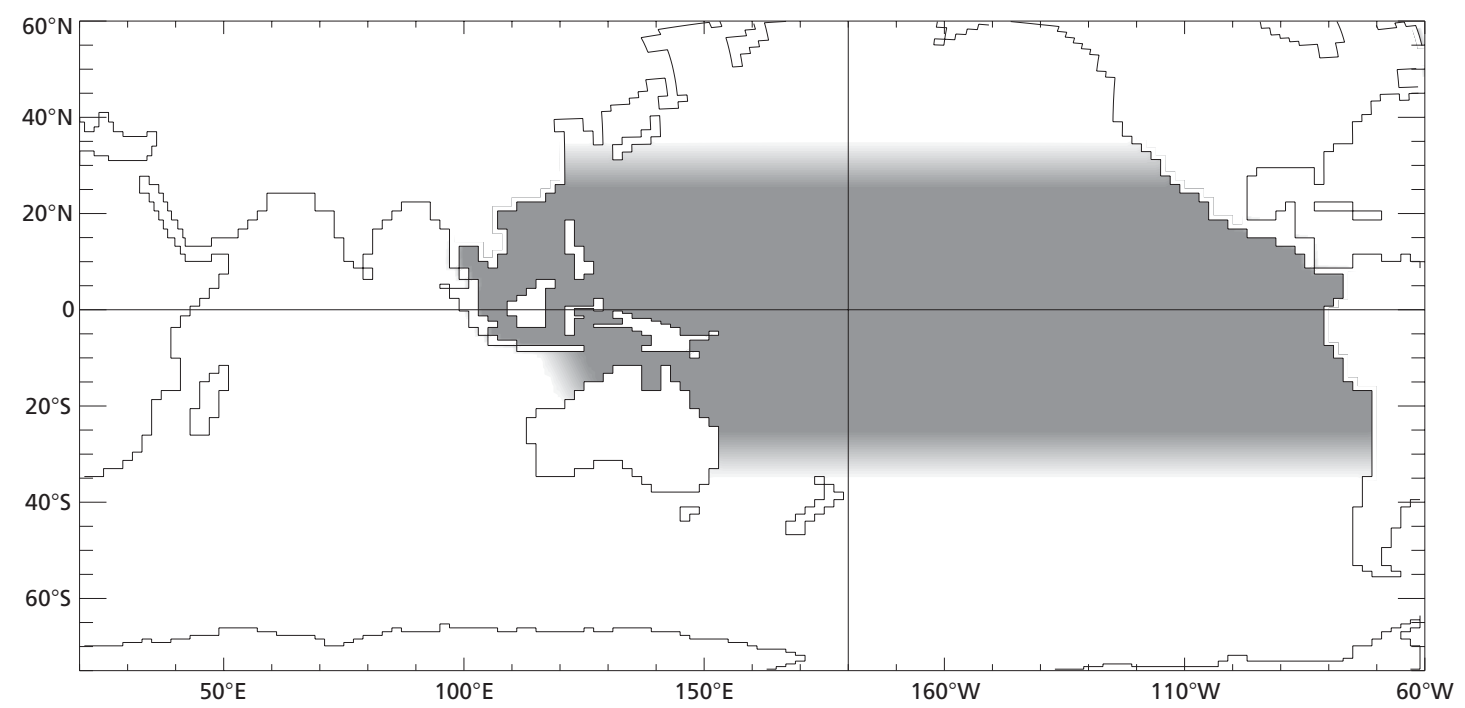

FIG. 8. The zone in the tropical Pacific Ocean in which coupling was constrained, shown on the ORCA2 ocean model grid. Linearly interpolated transition zones exist between 25 and $35^{\circ} \mathrm{N} / \mathrm{S}$, and in the ITF region between 125 and $135^{\circ} \mathrm{W}$ at $9^{\circ} \mathrm{S}$, with a slope of $60^{\circ}$ in lat/lon space. In experiment noENSO, the wind stress seen by the ocean was blended (fully inside the zone, partially in the transition zones) with the REF mean seasonal cycle winds, at monthly resolution with linear interpolation in time. 

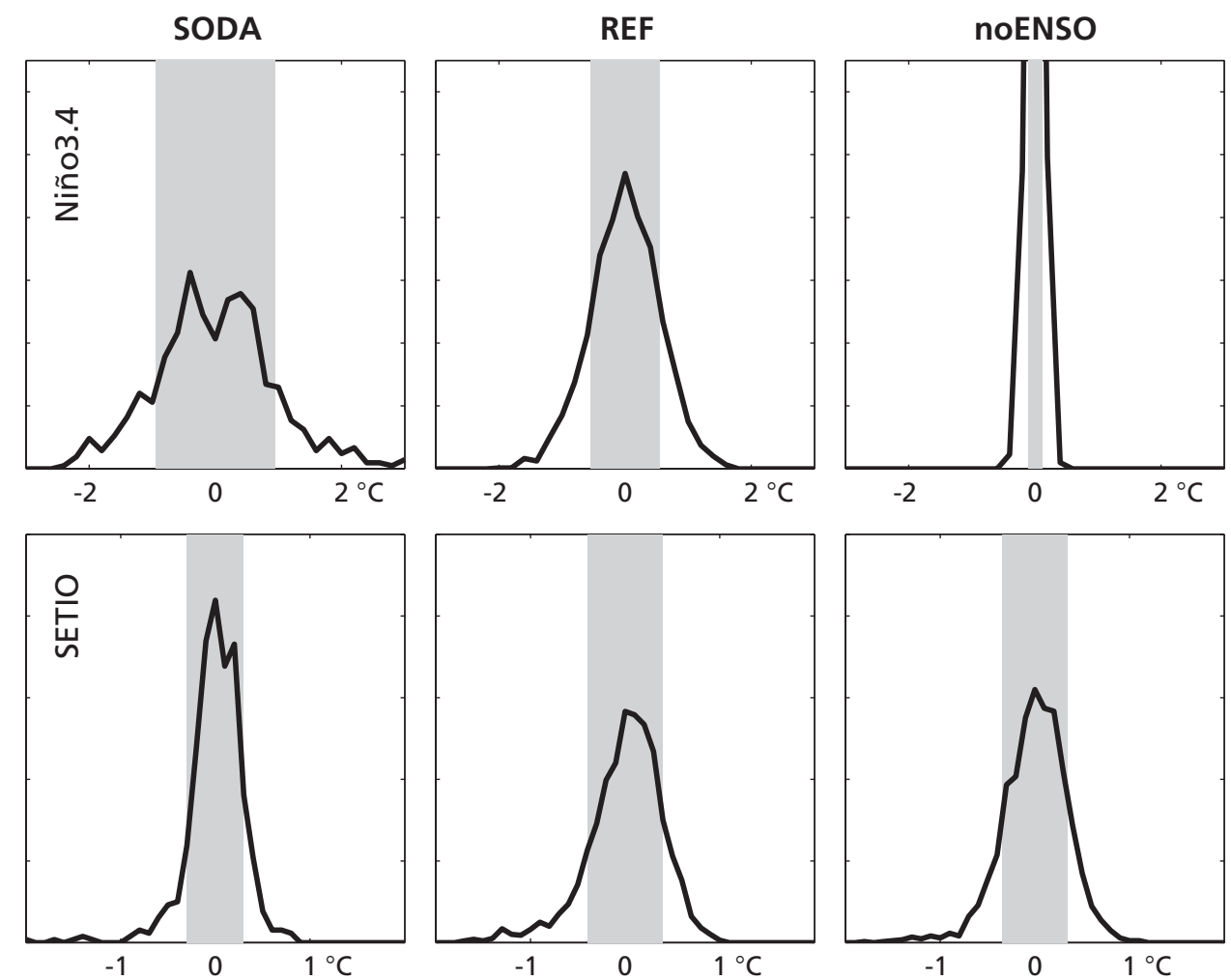

FIG. 9. Normalized histograms of the Niño3.4 and SETIO monthly SST anomaly timeseries from the SODA analysis, REF and noENSO. The vertical axis is arbitrary but to the same scale. The standard deviation of the distribution is marked by the grey shading. While Pacific variability has been effectively suppressed in noENSO, the SETIO remains nearly as active as REF. The negative tail in SETIO is somewhat reduced in the noENSO run, but still present. 


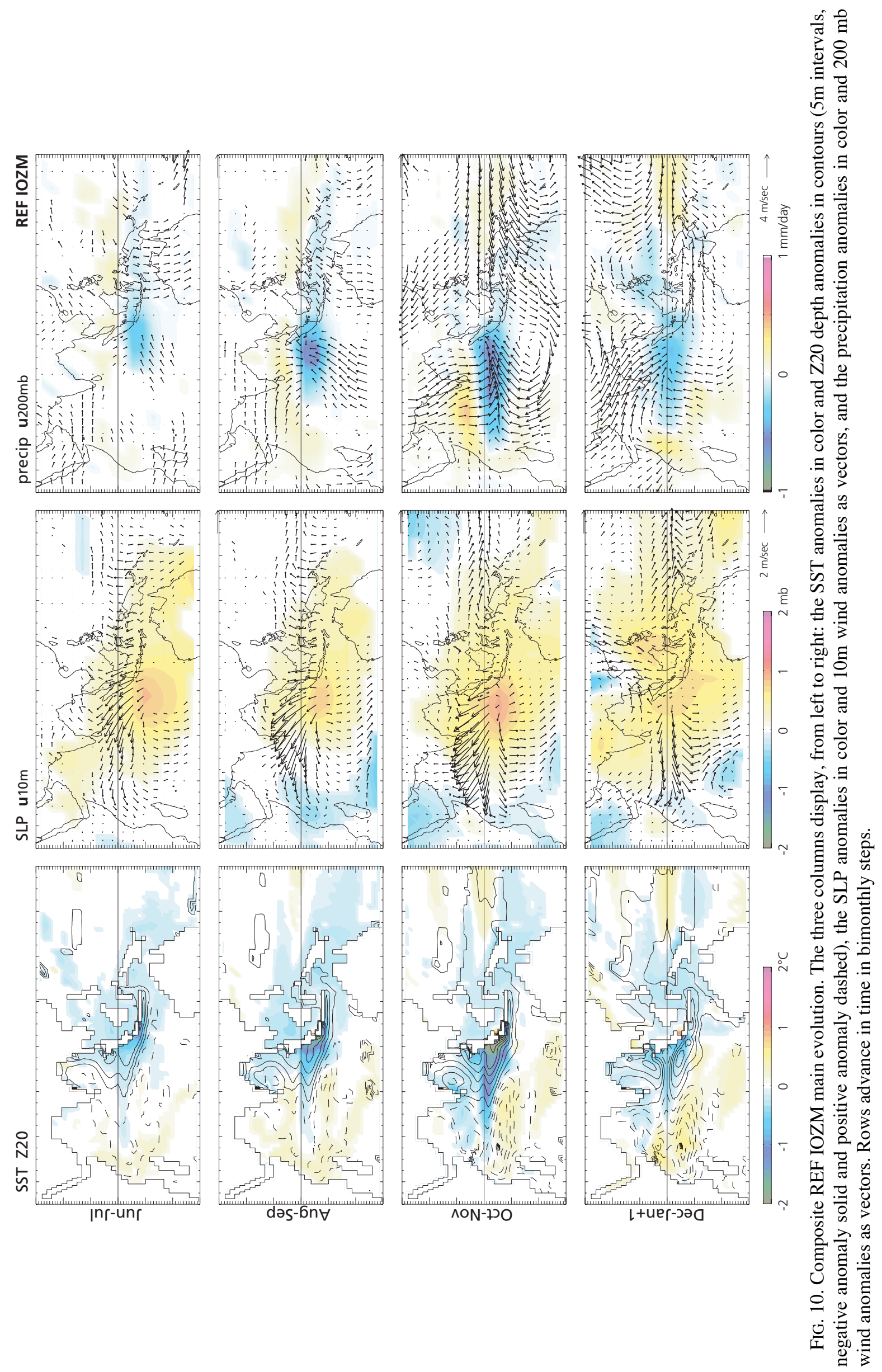



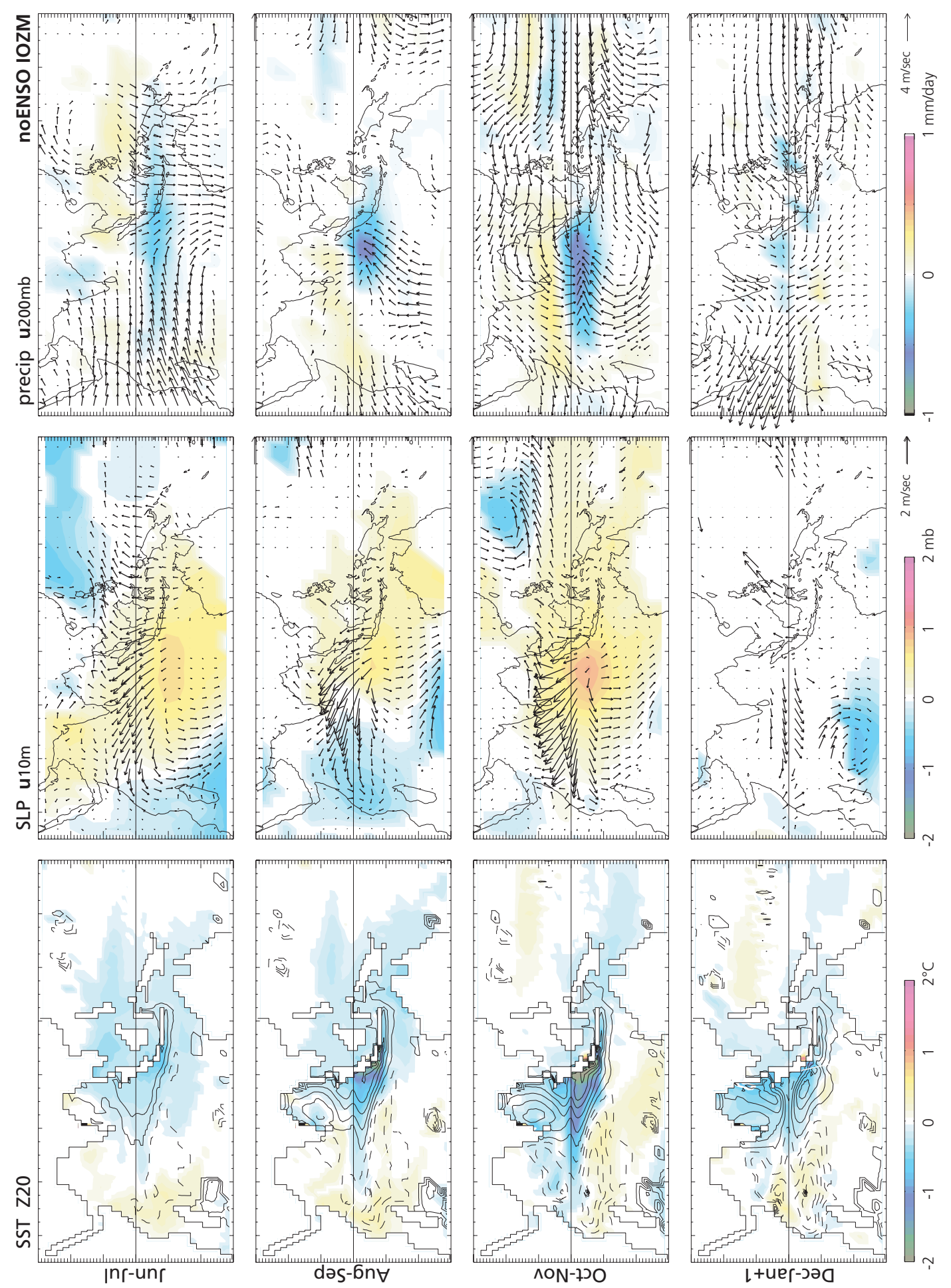

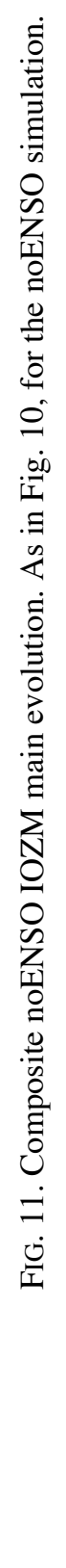



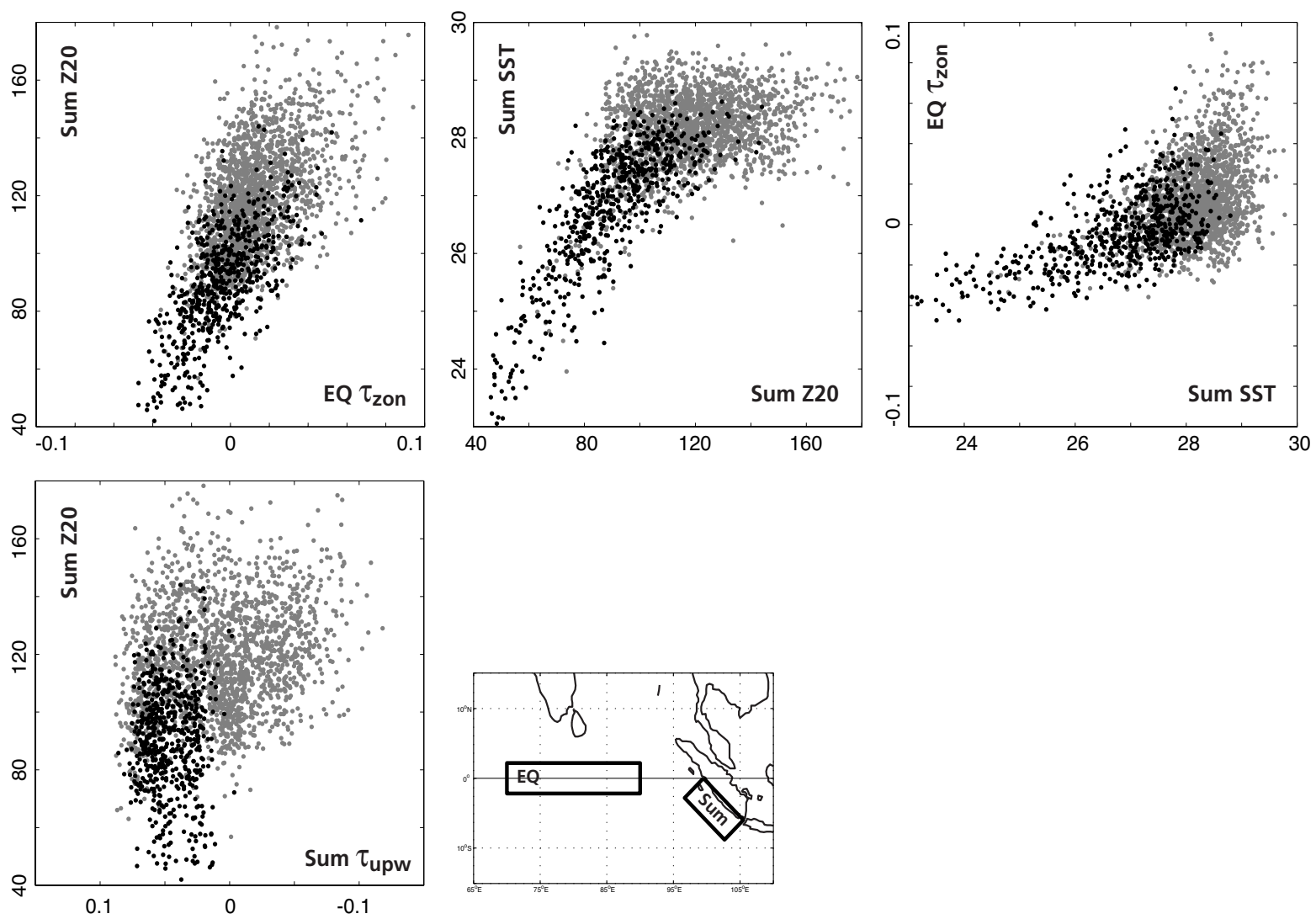

FIG. 12. Scatter plots of key absolute indices involved in the wind-thermocline-SST (Bjerknes-type) positive feedback from the noENSO simulation, with SON values in black, others in grey. From top, left to right, the zonal wind stress in an equatorial box spanning $60-90^{\circ} \mathrm{E}, 2^{\circ} \mathrm{S}-2^{\circ} \mathrm{N}$ vs. the $20^{\circ} \mathrm{C}$ isotherm depth in the box indicated off the coast of Sumatra, the Sumatra Z20 vs. Sumatra SST, and Sumatra SST vs. equatorial zonal wind stress. The lower left panel shows the relationship between the Sumatra alongshore upwelling component of the wind stress and $\mathrm{Z} 20$ in the same box.
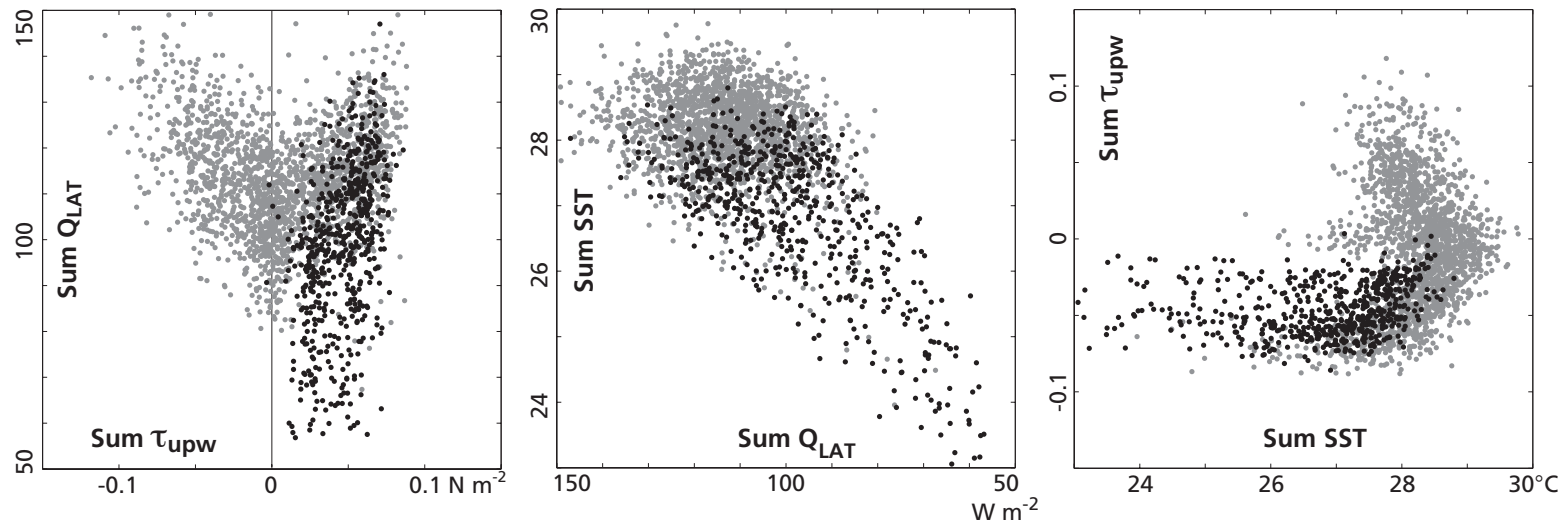

FIG. 13. Scatter plot of key indices involved in the wind-evaporation-SST coupled feedback from the noENSO simulation, SON values in black, others in grey. From left to right, the Sumatra alongshore component of the wind stress (which in all seasons is the major axis of the wind) vs. the Sumatra latent heat loss from the ocean, Sumatra latent heat loss vs. Sumatra SST, and Sumatra SST vs. Sumatra alongshore wind stress. This is not a positive feedback in the model during the IOZM season. 

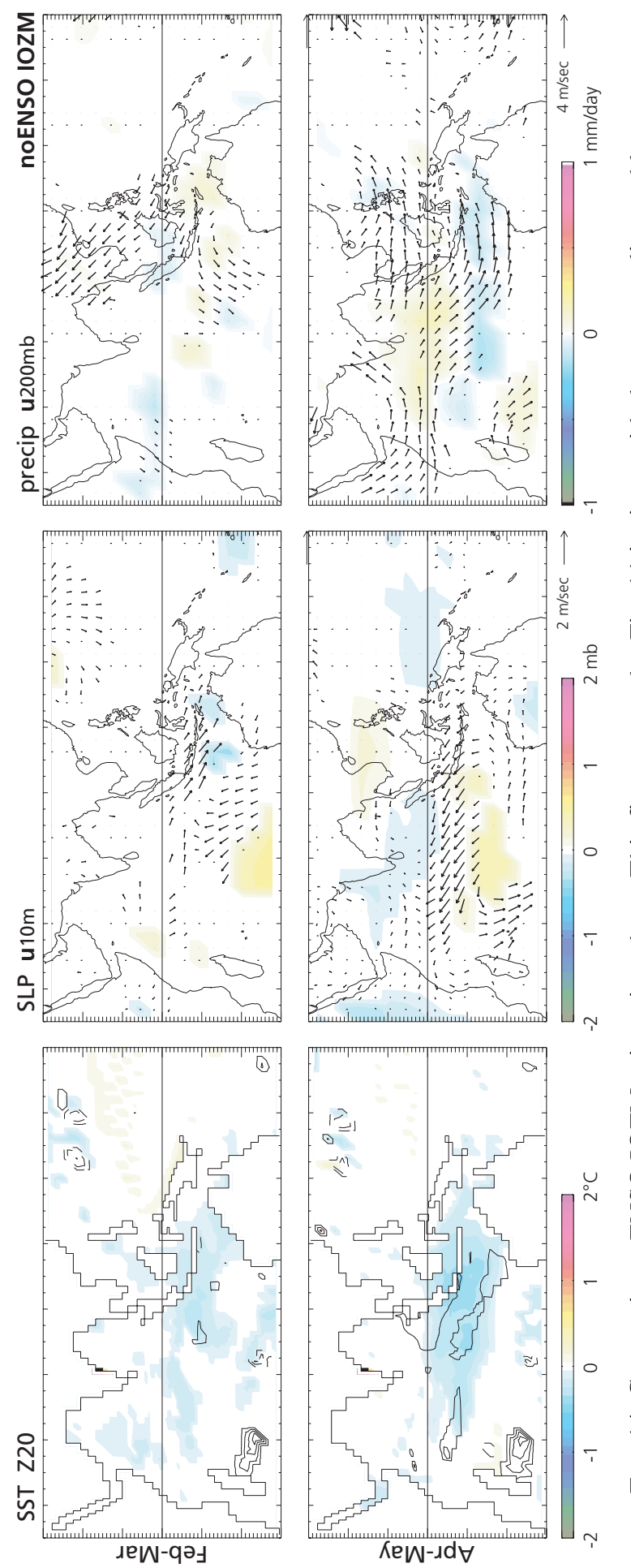

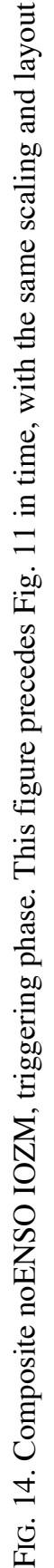




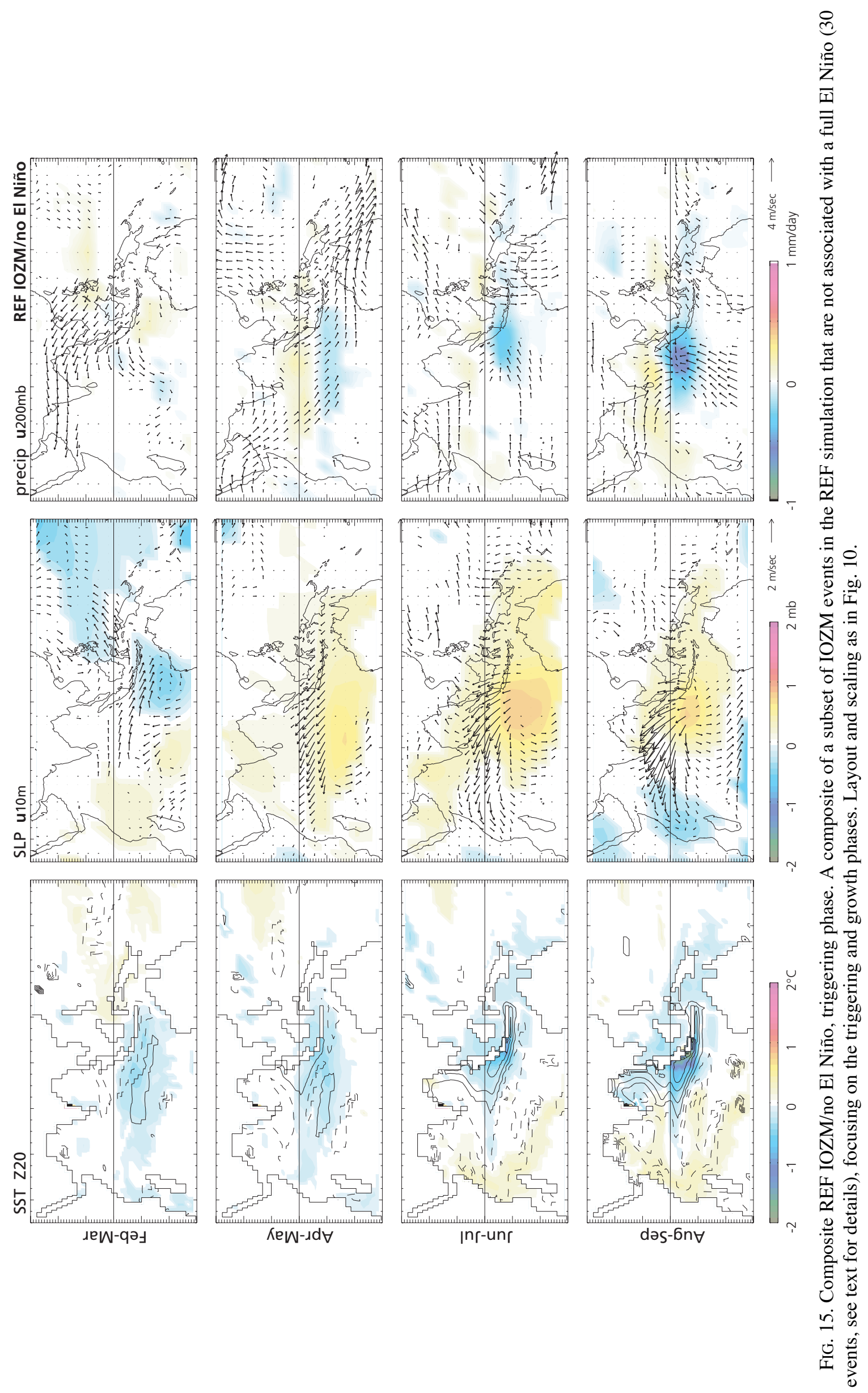




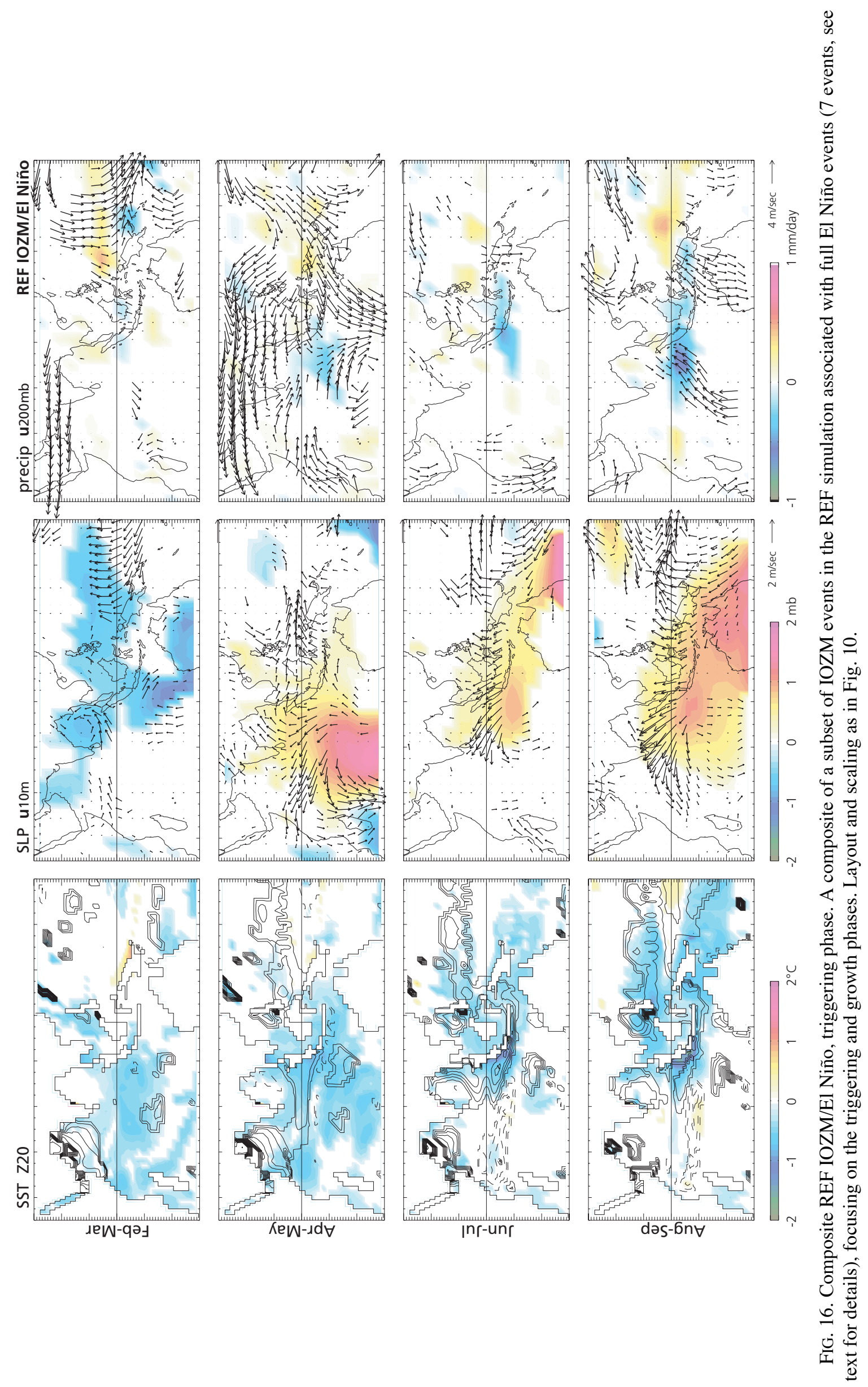




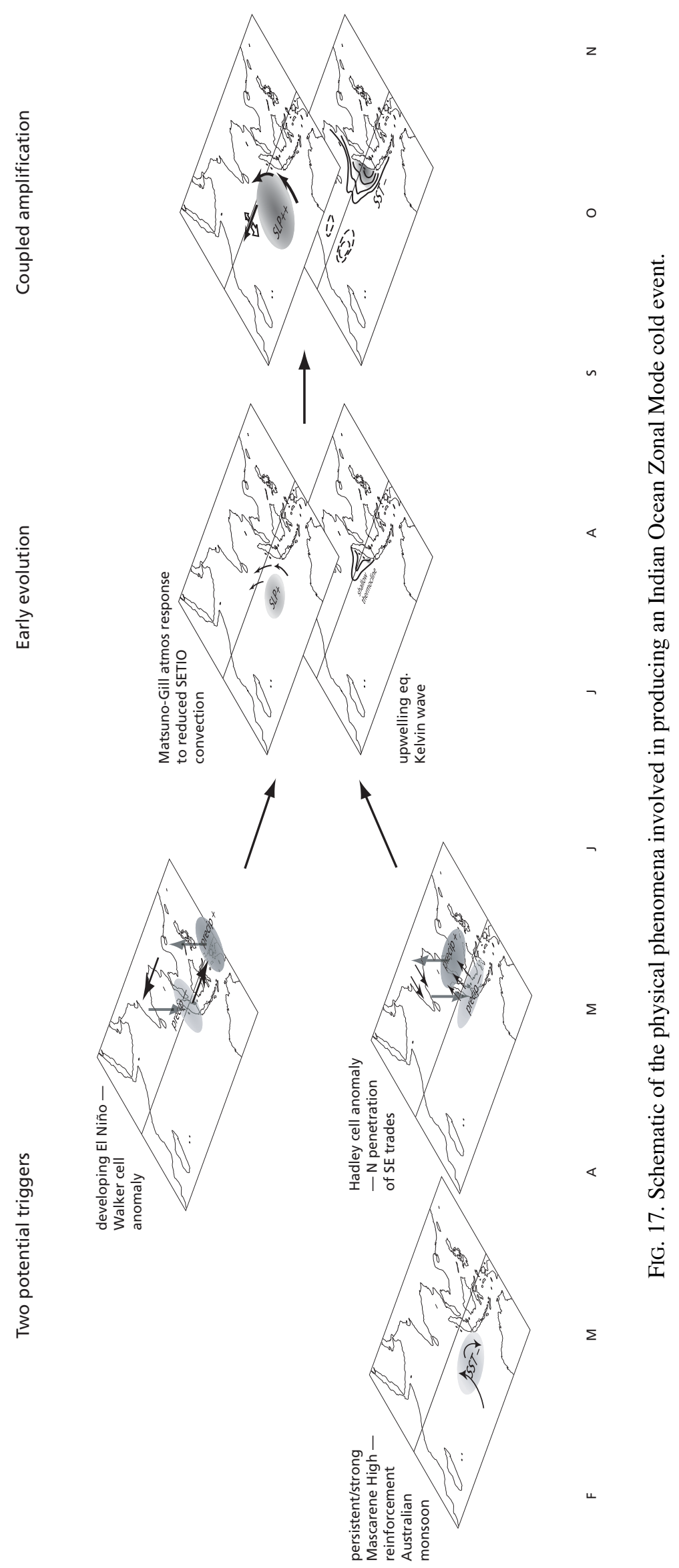




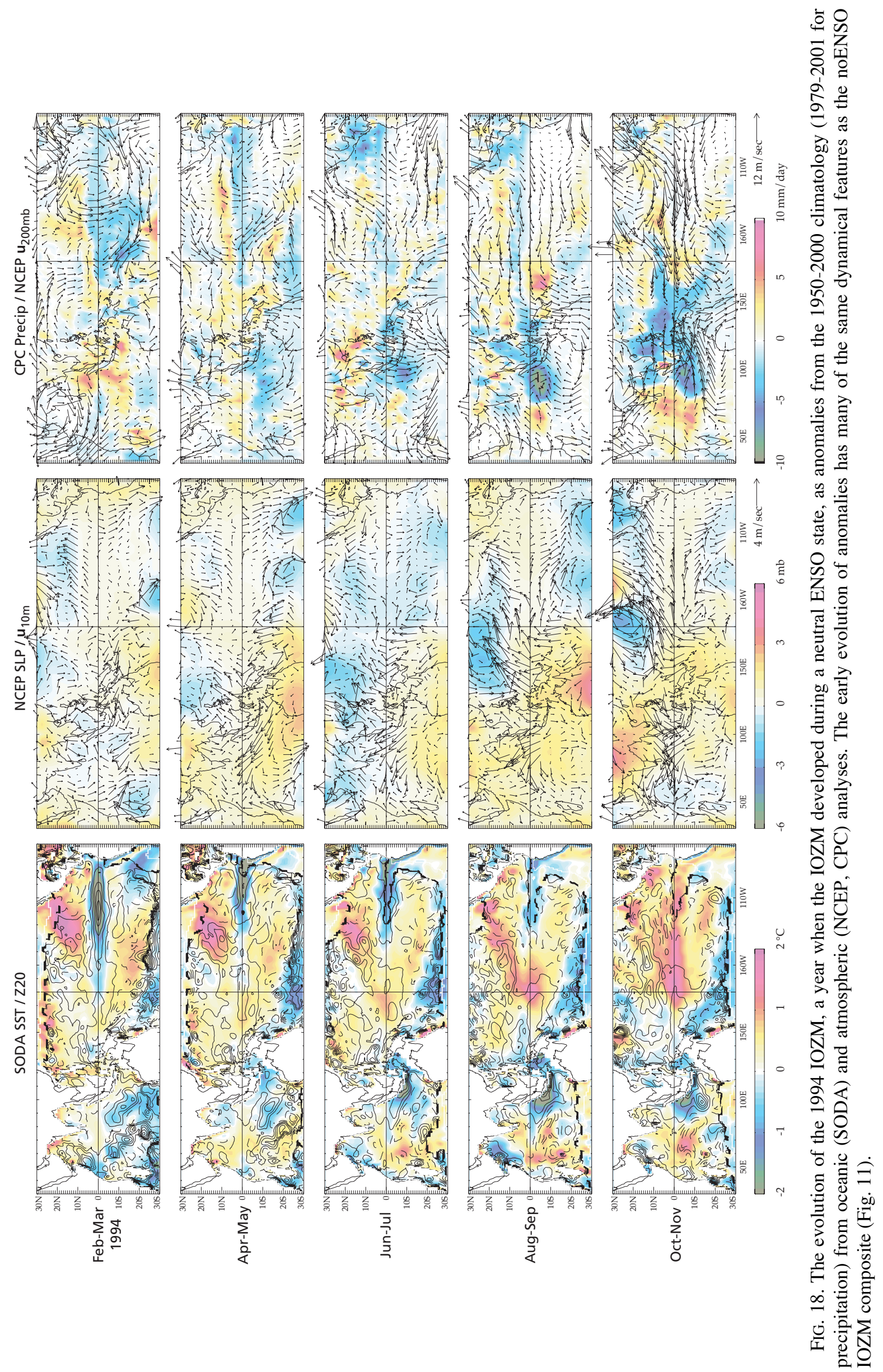





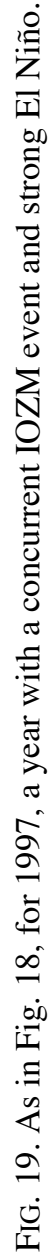
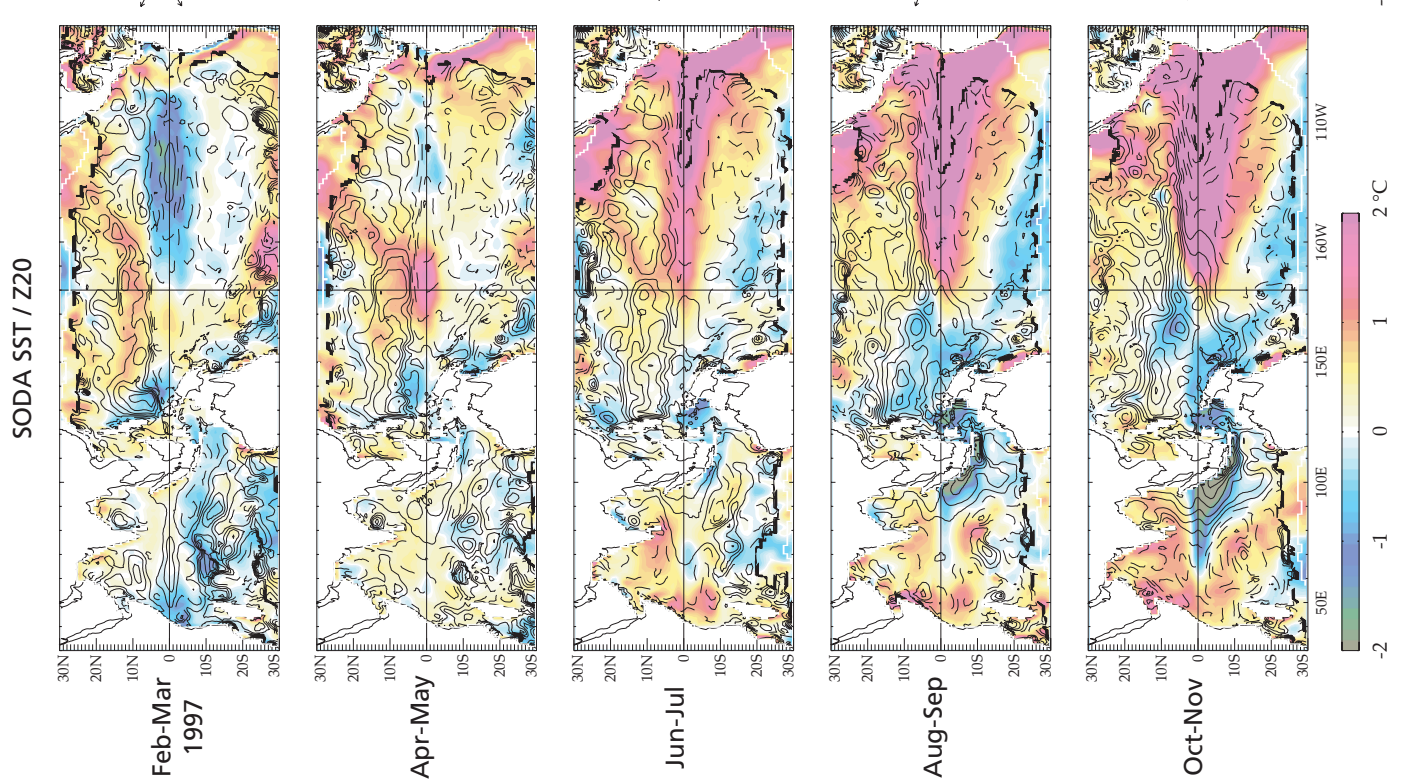